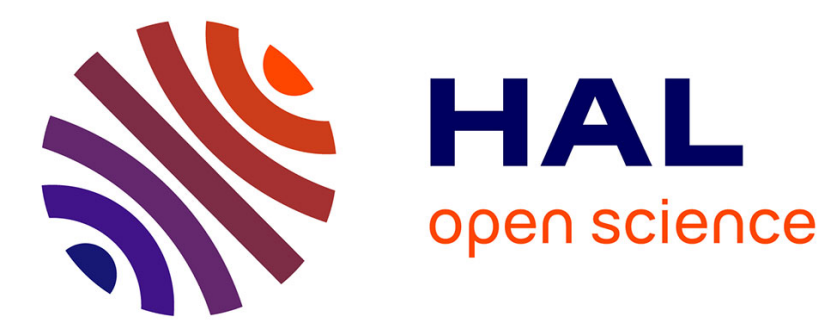

\title{
Experimental study of liquid spreading in structured packings
}

Manel Fourati, Véronique Roig, Ludovic Raynal

\section{To cite this version:}

Manel Fourati, Véronique Roig, Ludovic Raynal. Experimental study of liquid spreading in structured packings. Chemical Engineering Science, 2012, vol. 80, pp. 1-15. 10.1016/j.ces.2012.05.031 . hal00786392

\section{HAL Id: hal-00786392 \\ https://hal.science/hal-00786392}

Submitted on 8 Feb 2013

HAL is a multi-disciplinary open access archive for the deposit and dissemination of scientific research documents, whether they are published or not. The documents may come from teaching and research institutions in France or abroad, or from public or private research centers.
L'archive ouverte pluridisciplinaire HAL, est destinée au dépôt et à la diffusion de documents scientifiques de niveau recherche, publiés ou non, émanant des établissements d'enseignement et de recherche français ou étrangers, des laboratoires publics ou privés. 


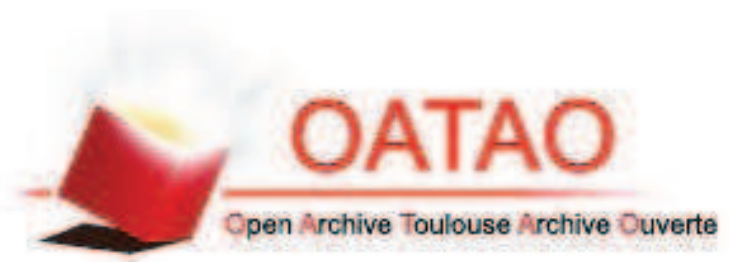

\section{Open Archive Toulouse Archive Ouverte (OATAO)}

OATAO is an open access repository that collects the work of Toulouse researchers and makes it freely available over the web where possible.

This is an author-deposited version published in: http://oatao.univ-toulouse.fr/ Eprints ID: 8036

To link to this article: DOI:10.1016/j.ces.2012.05.031

URL: http://dx.doi.org/10.1016/j.ces.2012.05.031

\section{To cite this version:}

Fourati, Manel and Roig, Véronique and Raynal, Ludovic Experimental study of liquid spreading in structured packings. (2012) Chemical Engineering Science, vol. 80. pp. 1-15. ISSN 0009-2509

Any correspondence concerning this service should be sent to the repository administrator: staff-oatao@listes.diff.inp-toulouse.fr 


\title{
Experimental study of liquid spreading in structured packings
}

\author{
M. Fourati ${ }^{\mathrm{a}, \mathrm{b}}$, V. Roig ${ }^{\mathrm{b}}$, L. Raynal ${ }^{\mathrm{a}, *}$ \\ a IFP Energies nouvelles, Rond Point de l'échangeur de Solaize, BP 3, 69360 Solaize, France \\ ' ${ }^{\mathrm{b}}$ Institut de Mécanique des Fluides de Toulouse, Université de Toulouse (INPT, UPS) and CNRS, Allée Camille Soula, 31400 Toulouse, France
}

\section{R E S E A R C H H I G H L I G H T S}

- Original measurements of liquid dispersion in a counter-current packed bed equipped with a modern high efficiency packing.

- Use of a high resolution gamma ray system.

- In a column of large size diameter with different fluids over a large range of operating conditions.

- A comparison of the experiments with a 2D model using a spread factor.

- Data are of high interest for further CFD modeling since they allow for the determination of closure laws of gas-liquid flow in packed beds.

Keywords:

$\mathrm{CO}_{2}$ capture

Structured packing

Two-phase flow

Distillation

Absorption

Tomography

\begin{abstract}
A B S T R A C T
Optimization of industrial gas-liquid columns dedicated to $\mathrm{CO}_{2}$ capture requires prediction of liquid distribution within packed beds. In this context, liquid hold-up as well as liquid spreading from a source point have been investigated for Mellapak 250.X structured packing. Local liquid hold-up measurements have been achieved in a $400 \mathrm{~mm}$ diameter column by means of gamma-ray tomography with operation in the counter-current mode at different positions downstream the source point injection. Liquid hold-up and retention map measurements have been performed for two fluid systems: Air/Water and Air/MEA 30 wt\%. A correlation that relates global liquid hold-up and liquid load taking into account liquid viscosity is proposed. This correlation has been further used to determine spread factors using a simple dispersion model for all investigated operational conditions. Liquid dispersion model is found to well reproduce experimental data in the range of operational conditions that were tested which enables to determine spread factors for various operating conditions. The spread factor is observed not to vary with the liquid load, the gas capacity factor in the range of $20-80 \%$ of flooding or the liquid viscosity. This led us to stipulate that liquid dispersion is controlled by packing geometry only. Nevertheless, the effect of surface tension on liquid hold-up and dispersion is discussed since its effect is not fully understood and calls for further experiments if one wants to apply those results for hydrocarbons.
\end{abstract}

\section{Introduction}

Packed columns are widely used for gas/liquid absorption processes since they generate subsequent exchange surface between phases with limited pressure drop in comparison with other technologies such as tray columns. Such packed columns are considered for $\mathrm{CO}_{2}$ capture technologies, either for $\mathrm{CO}_{2}$ post-combustion with amines absorption unit or for $\mathrm{CO}_{2}$ oxy-combustion with air separation unit. It is considered by IEA that $\mathrm{CO}_{2}$ capture technologies could handle up to $19 \%$ of $\mathrm{CO}_{2}$ emissions. However, the deployment of this technology requires process optimization with associated cost

\footnotetext{
*Corresponding author. Tel.: +33 4377025 27; fax: +33 437702009.

E-mail address: ludovic.raynal@ifpen.fr (L. Raynal).
}

reduction, both in terms of operational expenditures (Opex) and capital expenditures (Capex). As underlined in Raynal et al. (2011), many studies concerning post-combustion processes development deals with solvent selection and less work is dedicated to column design optimization. Such an optimization is required in order to decrease the cost of investment of capture processes. It can be achieved either by developing new high performance packings and/or by achieving the most adequate design of packed columns. Such an optimum design is linked to the choice of packing, the number of packed beds and their height, the interaction between gas and liquid distributors with the gas/liquid flow within the packed bed. All this is strongly linked to liquid dispersion and gas/liquid interaction in the packed bed.

The two-phase flow in a packing consists of thin trickling liquid films sheared by co- or counter-current gas flow that 
circulates in communicating tortuous channels. The resulting flow in a packed column is complex since it induces interactions between various scales going typically from liquid films $(100 \mu \mathrm{m})$ to column scale $(10 \mathrm{~m})$. Packings include structured and random packings that have different capacities and separation performances permanently improved by manufacturers (Olujic et al., 2006). Unfortunately, little work is done in terms of extrapolation that ensures that performances obtained at laboratory scale (column diameter usually less than $400 \mathrm{~mm}$ for bed height about $1 \mathrm{~m}$ ) would be obtained at large scale (bed height up to $10 \mathrm{~m}$ ). In order to design packed columns, experimental studies have been performed to determine global pressure drop through packed bed as well as liquid hold-up necessary for prediction of mass transfer performances. A lot of these studies focused on packings hydrodynamic and mass transfer characterization, all considering homogeneous flow configuration (Iliuta and Larachi, 2001; Alix and Raynal, 2008; Sidi-Boumedine and Raynal, 2005). Pressure drop, hold-up and transfer coefficients models coming from experimental knowledge are therefore built upon the assumption of homogeneous flow distribution in the packed bed. This assumption is far from being relevant at industrial scale since maldistributions do occur even with optimized liquid and gas distributors in the column inlets. The limiting effect of maldistribution on efficiency has been recognized in many studies since it impacts pressure drop and may reduce the effective exchange area between phases (Olujic et al., 2006). The maldistribution of liquid flow is the most detrimental in terms of separation efficiency. However, gas flow tends to maintain a relatively homogenous distribution in the packed bed and does not affect packing efficiency even in case of severe gas initial maldistribution as reported in the work of Mohamed Ali et al. (2003). In order to limit the detrimental effect on separation performances, liquid collectors and redistributors of liquid are generally inserted at different axial positions of the column. In order to homogenize the flow, length intervals between the redistribution devices need to be optimized. Traditionally, such bed lengths are taken equivalent of ten to twenty theoretical trays according to Hoek et al. (1986). These industrial design rules are still empirical and often limited to given distributor and packing. In order to improve design rules or numerical modeling of packed beds, a better knowledge of the mechanisms involved in the liquid dispersion phenomenon is required. This has been the motivation for this study.

Dispersion of the liquid across the packed bed results from several mechanisms: (i) the liquid films' flow on walls of complex geometry more or less random with corrugations, abrupt slope changes, anisotropic orientations etc. that modulate local liquid volume fraction; (ii) the liquid films are sheared by turbulent gas flow that may also generate liquid volume fraction fluctuations; (iii) finally any heterogeneity of solid surface physical properties may generate differential surface wetting. All these random mechanisms induce a global transport of both phases named dispersion which acts in all directions. The modeling of the liquid dispersion is still quite limited. Numerical simulation of twophase flow using two-fluid models have recently been used to predict local distributions of phases and occurrence of maldistributions in catalytic packed beds (Lappalainen et al., 2009; Mewes et al., 2009), the latter being characterized by small voidage (less than $50 \%$ ) and by small characteristic length, the diameter of the particles being one order of magnitude less than the characteristic length in standard structured packings. Local distribution of phases is partially governed by dispersion in these models. Lappalainen et al. (2009) identified two dispersion mechanisms; mechanical dispersion that is induced by the random local geometry of the packing and capillary dispersion due to capillary pressure gradients. The authors adopted phenomenological closure laws for dispersion terms that reproduce experimental liquid spreading. Taking correctly into account the dispersion in generic flow configurations requires, however, specific development of closure laws. First a better physical analysis of the mechanisms governing dispersion of liquid in packed beds is required and second adequate dispersive terms should then be added to fundamental balances of the liquid.

Many previous experimental studies have focused on liquid dispersion. Such measurements, considering dispersion from a point source, have been performed in catalytic beds and packed beds equipped with random packings and corresponding spread factors have been determined. The spread factor is linked to liquid dispersion model in a local liquid transport model (see Hoek et al., 1986 for precise definition of spread factor). In the case of random packings, experiments with liquid dispersion from a point source have been carried out and radial dispersion was reported to be a driving mechanism in liquid transport. Onda et al. (1972) carried out dispersion experiments on $4 \mathrm{~mm}$ Berl saddles and Raschig rings packing types for liquid loads varying from 3 to $30 \mathrm{~m}^{3} / \mathrm{m}^{2} \mathrm{~h}$ and with no gas flow. Authors varied ring sizes as well as liquid surface tension and noticed that spread factor does not depend on liquid load but only on ring size and surface tension. Same behavior, regarding the effect of ring size on spread factor, was observed by Bemer and Zuiderweg (1978). These authors did dispersion experiments from a point source with no gas on glass and Teflon coated Raschig rings. Neither the effect of solid wettability nor the surface tension on dispersion was reported for the range of rings sizes considered ( 1 to $3 \mathrm{~cm}$ ). Both cited studies used collectors on bottom of the packed bed to access liquid flow rate radial profile; calculated liquid spread factors were found to be in the range of $1-4 \mathrm{~mm}$ for the considered random packings.

Modern metallic random and structured packings known for their high performance (high void fraction, low pressure drop, high effective exchange area) have been widely studied as well. However, no spread factors were previously calculated on structured packing even if liquid distribution in such packings has been explored. Olujic et al (2006) carried out liquid distribution measurements on Montz Pak B1-250M and Montz Pak B1-250 packings using liquid collectors at different bed heights. These authors varied liquid loads up to $60 \mathrm{~m}^{3} / \mathrm{m}^{2} \mathrm{~h}$ using a narrow trough distributor that has a drip point density of $100 \mathrm{~m}^{-2}$. They applied counter-current gas flow at pre-loading, loading and flooding conditions and characterized liquid distribution quality by calculating a global maldistribution indicator (see Hoek et al., 1986 for definition of maldistribution indicator). This indicator characterizes the heterogeneity of liquid distribution whatever its origin and is therefore not simply linked to dispersion mechanisms. Toye et al. (2005) have also studied liquid distribution in a $10 \mathrm{~cm}$ diameter column packed with KATAPAKSP.12 structured packing. Authors measured liquid local as well as section-averaged hold-ups for liquid rates ranging from 13 to $38 \mathrm{~m}^{3} / \mathrm{m}^{2} \mathrm{~h}$ without gas flow restricting, thus, their results to lowinteraction gas/liquid regimes.

In the present work, a quantitative characterization of liquid distribution in a counter-current gas/liquid packed column filled with Mellapak 250.X structured packing has been carried out using gamma ray tomography. We focused on Mellapak 250.X structured packing which is very close to the Mellapak 250.Y, a standard in the distillation and absorption industry, but allows for higher capacities which is a key point for $\mathrm{CO}_{2}$ capture.

The use of tomography system allows to have an insight into the packed bed at different axial positions while the column is operating and allows following axial flow evolution which cannot be done with liquid collectors used in previous studies. Liquid was injected at top of the column through orifices situated at the 
center of a chimneys' tray and counter-current gas flow is applied using a diffuser at the bottom of the column. Liquid hold-up measurements were carried out over a large range of experimental conditions including different liquid loads and gas kinetic factors varying from $20 \%$ to $80 \%$ with respect to flooding conditions. Liquid spread factors have been, therefore, determined in order to characterize liquid dispersion.

In this paper, a simple liquid spreading model is first proposed considering the spreading of a point source within an infinite packed bed in Section 2. Second, the experimental set-up and the gamma ray measuring system are described in Section 3. Finally raw liquid hold-up maps obtained from tomography as well as spread factors derived from averaged liquid hold-up are presented and accuracy of radial dispersion model is discussed (Section 4).

\section{Liquid spreading model: global advection-diffusion model}

Liquid spreading in packed beds has been explored in several studies, mainly in the case of random packings. Liquid distribution measurements have been carried out on packed beds since long ago using collectors that give access to liquid flow rate distribution at column bottom. Based on these measurements, a model using advection-diffusion transport equation for local superficial liquid velocity $q_{L}$ averaged at a meso-scale has been demonstrated to give good representation of experimental data when liquid is fed from a source point on top of packed bed (Cihla and Schmidt, 1958; Hoek et al., 1986; Bemer and Zuiderweg, 1978; Edwards et al., 1999). Such model predicts average liquid flow-rate over annular sectors of radius $R$. Spreading can be, thus, characterized using a specific length that is referred to by "spread factor" $D_{r}$ and which could be compared to the particle size or hydraulic diameter through a Peclet number. The proposed advection-diffusion model for liquid spreading is given by Eq. (1) where $z$ and $r$ indicate, respectively, the axial and the radial positions in a cylindrical coordinates system $\left(\vec{e}_{z}, \vec{e}_{r}, \vec{e}_{\theta}\right)$ while $q_{L}(r, z)$ accounts for the superficial liquid velocity. The possibility of applying such a model for structured packings has been discussed by Edwards et al. (1999) who stipulated that the slow liquid spreading in structured packings $\left(D_{r} \ll D\right)$ implies that liquid spreading takes place over many packing layers. The global dispersion can be, thus, considered as isotropic in the cross section and the model given by Eq. (1) can be applied:

$\frac{\partial q_{L}(r, z)}{\partial z}=D_{r}\left(\frac{1}{r} \frac{\partial q_{L}(r, z)}{\partial r}+\frac{\partial^{2} q_{L}(r, z)}{\partial r^{2}}\right)$

Onda et al. (1972) suggested a wide variety of boundary conditions to solve Eq. (1); in order to simplify resolution of the model, which holds for axial symmetry of the flow field, the assumption of an infinite medium is considered in this work which means that no wall effect on liquid spreading is taken into account as expressed in the boundary conditions given by

$$
\left.\begin{array}{l}
q_{L}(0,0)=\frac{Q_{L 0}}{S} \\
q_{L}(r, 0)=0 \\
q_{L}(\infty, z)=0 \\
\left.\frac{\partial q_{L}(r, z)}{\partial r}\right|_{r=0}=0
\end{array}\right\}
$$

The analytical solution of the system formed by Eqs. (1) and (2) can be obtained easily and is given by Eq. (3) where $Q_{0}\left(\mathrm{~m}^{3} / \mathrm{s}\right)$ denotes the total liquid flow rate at the top of the column. From Eq. (3) it is easy to deduce Eq. (5) using definitions given by Eq. (4) that introduces cumulated liquid flow rate $Q_{L}$. As can be seen from Eq. (5), the spread factor, $D_{r}$, can thus be determined from a plot of $r^{2} / z$ against $\operatorname{Ln}(1-x)$ where $x$ accounts for the fraction of liquid flowing through an annular area of radius $r$.

A general analytical solution of Eq. (1) for finite media where liquid reaches the column walls can be found in literature (Porter and Jones, 1963; Cihla and Schmidt, 1958). This solution gives access to spread factor before liquid reaches column walls and allows further determination of wall liquid flow rate. Spread factor can be thus determined independently from wall liquid flow rate using infinite medium assumption.

In this study, as will be mentioned further, we focus on the infinite medium solution to determine spread factor:

$$
\begin{aligned}
& q_{L}(r, z)=\frac{Q_{L 0}}{4 \pi D_{r} z} \exp \left(-\frac{r^{2}}{4 D_{r} z}\right) \\
& \left.\begin{array}{l}
Q_{L}=\int_{0}^{r} \int_{0}^{2 \pi} q_{L}\left(r^{\prime}, z\right) r^{\prime} d r^{\prime} d \theta \\
x=\frac{Q_{L}}{Q_{L 0}}
\end{array}\right\}
\end{aligned}
$$

$$
\frac{r^{2}}{z}=-4 D_{r} \operatorname{Ln}(1-x)
$$

This model will be used in combination with the measurements of the liquid hold-up in order to deduce, from the experimental data, the values of the spread factor, $D_{r}$, for the operating conditions considered.

\section{Experimental study}

\subsection{Set-up and methodology}

The experiments were performed in a transparent axisymmetric Plexiglas column, $40 \mathrm{~cm}$ in diameter and $1.5 \mathrm{~m}$ in height. As can be seen in Fig. 1, the column was filled with six layers of structured packings Mellapak 250.X manufactured by Sulzer Chemtech. The packing geometry is characterized by a geometric area per unit volume of the column $a_{g}=250 \mathrm{~m}^{2} / \mathrm{m}^{3}$, a large porosity $\varepsilon=0.98$ and an inclination angle of the flow channels with horizontal direction of $\theta=60^{\circ}$. The packing elements, made of stainless steel, are $22 \mathrm{~cm}$ high and were alternatively rotated around the axis of the column by $90^{\circ}$ relative to each other in order to improve liquid distribution as usually recommended for industrial columns.

The column was operated in the counter-current flow mode. Liquid was fed at the top of the column using a separate-phases tray, and gas was fed at bottom using a gas distributor. Fig. 2 shows upper views of the two liquid distributors. Usually liquid is fed from orifices uniformly distributed on the tray surface and gas passes through 7 chimneys represented by the large circles in Fig. 2. The orifices used for liquid feeding have a diameter of $10 \mathrm{~mm}$ and chimneys are $50 \mathrm{~mm}$ in diameter. The height of the chimneys is equal to $22.9 \mathrm{~cm}$. Two distributors, denoted A and B, were used to cover the liquid loads ranging from 16 to $56 \mathrm{~m}^{3} / \mathrm{m}^{2} \mathrm{~h}$. For the experiments on liquid dispersion presented in this paper, liquid was fed from 6 or 11 orifices (see the colored dots in Fig. 2); the other orifices were blocked. This results in having a central jet that can be assimilated to a point source feeding configuration. Finally, Fig. 3 gives upper view of gas diffuser located at bottom of the column. It shows the locations of the 17 orifices used for gas injection. Each one has a diameter of $3 \mathrm{~mm}$.

Liquid hold-up distributions were measured via a tomographic method at various longitudinal positions $Z_{i}(i=1$ to 4$)$ given in Fig. $1\left(Z_{1}=13 \mathrm{~cm}, Z_{2}=19 \mathrm{~cm}, Z_{j}=44 \mathrm{~cm}, Z_{3}=55 \mathrm{~cm}\right.$ and $Z_{4}=91.5 \mathrm{~cm}$ in a reference frame where $Z=0$ at the top of the packing). The locations of the measurements were chosen in order to examine the dispersion of liquid along the column height, but also inside the top element of packing. Measurements 
a

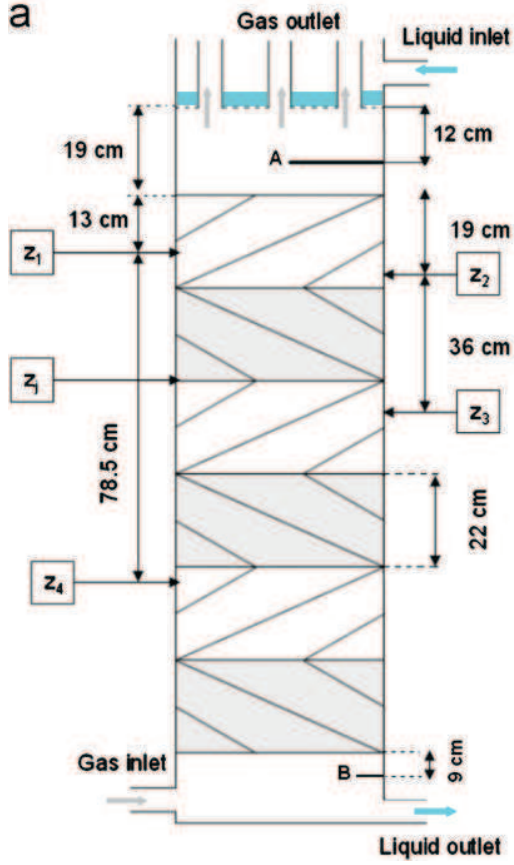

b
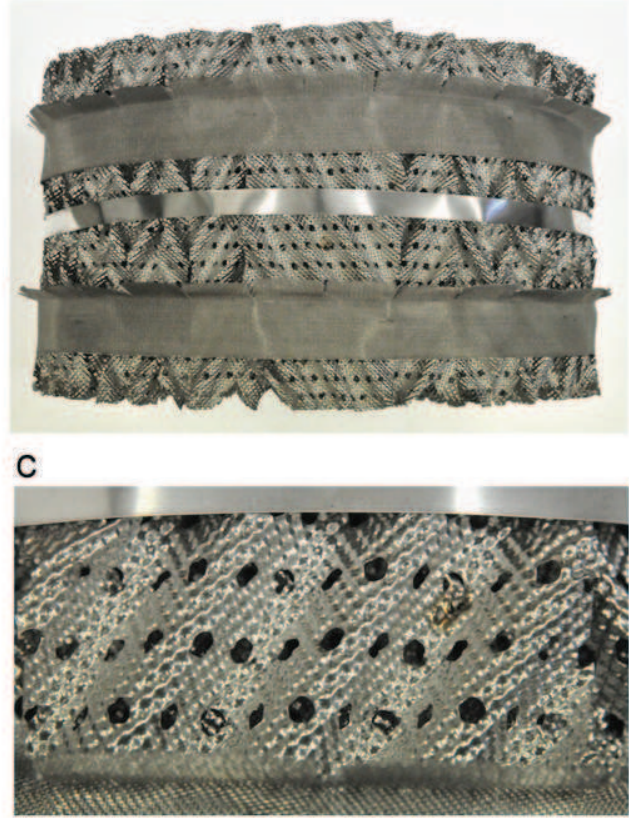

Fig. 1. (a) Sketch of the experimental apparatus; (b) picture of a $400 \mathrm{~mm}$ diameter block of Mellapak 250.X; (c) close-up picture.

A

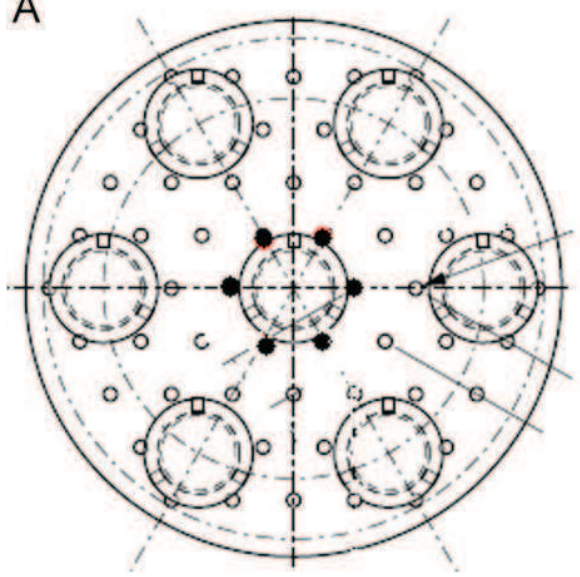

B

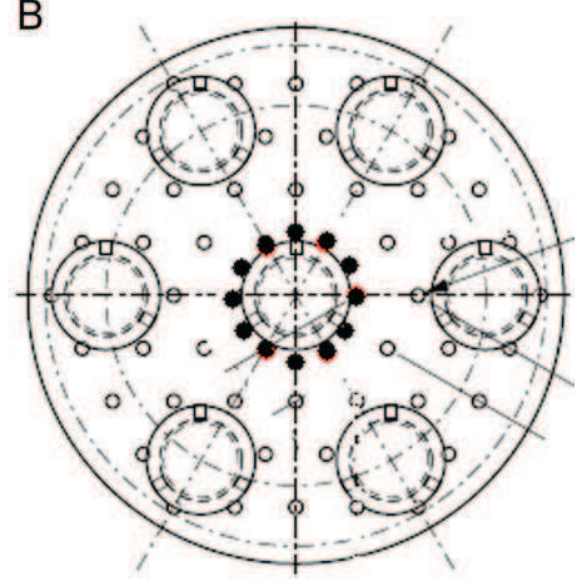

Fig. 2. Liquid distributors, left: A (for $16 \mathrm{~m}^{3} / \mathrm{m}^{2} \mathrm{~h}<q_{L}<36 \mathrm{~m}^{3} / \mathrm{m}^{2} \mathrm{~h}$ ), right: B (for $q_{L}=56 \mathrm{~m}^{3} / \mathrm{m}^{2} \mathrm{~h}$ ), dark dots correspond to the locations of orifices open for liquid injection.

were also performed at $Z=Z_{j}$ located at the junction between two elements in order to discuss the specific effect of the discontinuity of the geometry of the packings at this position. Pressure loss has also been investigated with measurements at points $A$ and $B$ as shown in Fig. 1 and located, respectively, at the center of the column cross-section and at $7 \mathrm{~cm}$ from the column wall.

\subsection{Measurement system: tomographic system}

A gamma-ray tomographic system has been used to measure spatial distributions of the liquid hold-up $h_{L}$ inside the column. The tomography methodology used in the present study has been fully characterized by Boyer and Fanget (2002) who studied the intrinsic performances of the apparatus as well as reconstruction algorithm accuracy. Gamma ray tomography has also been used previously by Sidi-Boumedine and Raynal (2005) as well as by Alix and Raynal (2008) in order to measure global liquid hold-up in packed beds equipped, respectively, with structured and random packings for homogeneous flows. The tomographic system, which is shown in Fig. 4, is composed of a gamma ray source that is Cesium ${ }^{137}$ of $300 \mathrm{mCi}$ in activity, a collimator and 32 detectors. The whole system has two degrees of freedom since it can slide over the column height and can rotate around the column axis. The 32 BGO photo-scintillators transducers (crystal of $\mathrm{BeGeO}$ ) are separated by spaces of $13 \mathrm{~mm}$. As far as the present work is concerned, the whole system was rotated to scan all the column section. The number of scans for a complete rotation was set at 64 . The spatial resolution of the measurement depends only on the number of angular positions of the rotating system which can be adjusted by the operator. We have chosen an operating mode leading to a description of the cross section of the column of $40 \mathrm{~cm}$ in diameter with $128 \times 128$ pixels. This gives a spatial resolution equal to $3.1 \mathrm{~mm}$. The measuring time that corresponds to the time for which the column is submitted to the photon flux was set at $10 \mathrm{~s}$ for each angular position in order to have a good signal to noise ratio.

To determine the liquid hold-up, a calibration procedure is necessary because both liquid and solid absorb gamma rays. The calibration consists in measuring gamma ray attenuation with no liquid nor gas flows in the column (dry experiments). Measurements 


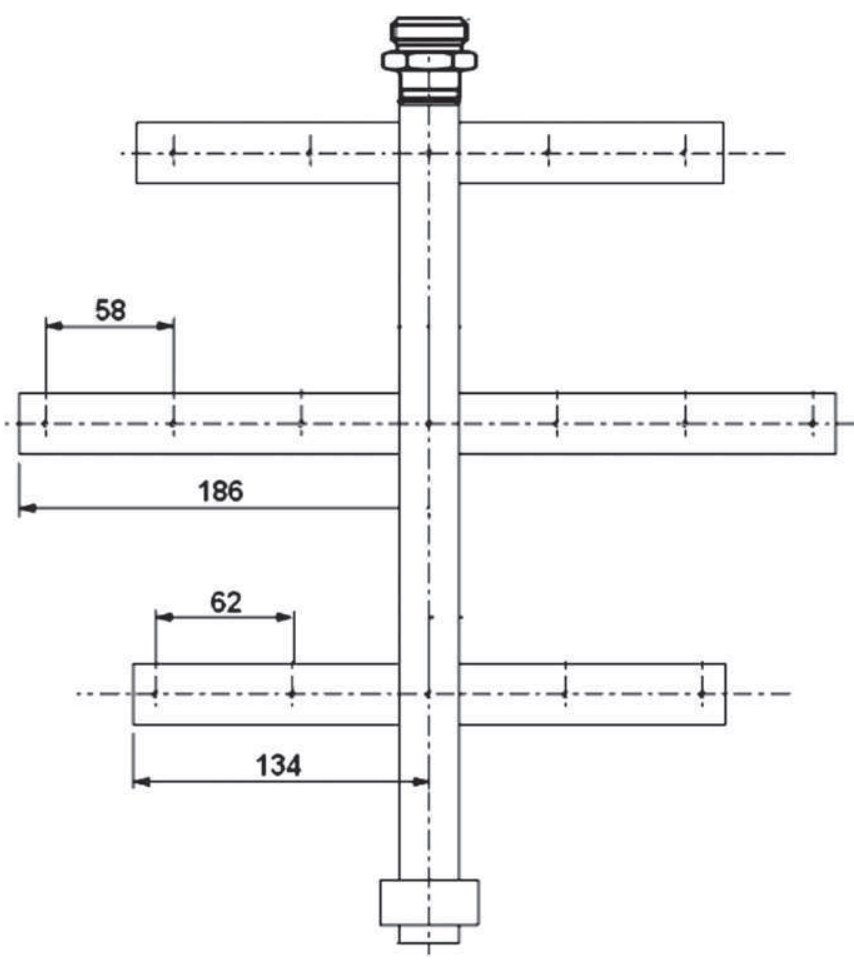

Fig. 3. Sketch of the upper view of gas diffuser (dimensions in $\mathrm{mm}$ ), in dark the locations of orifices allowing gas injection.

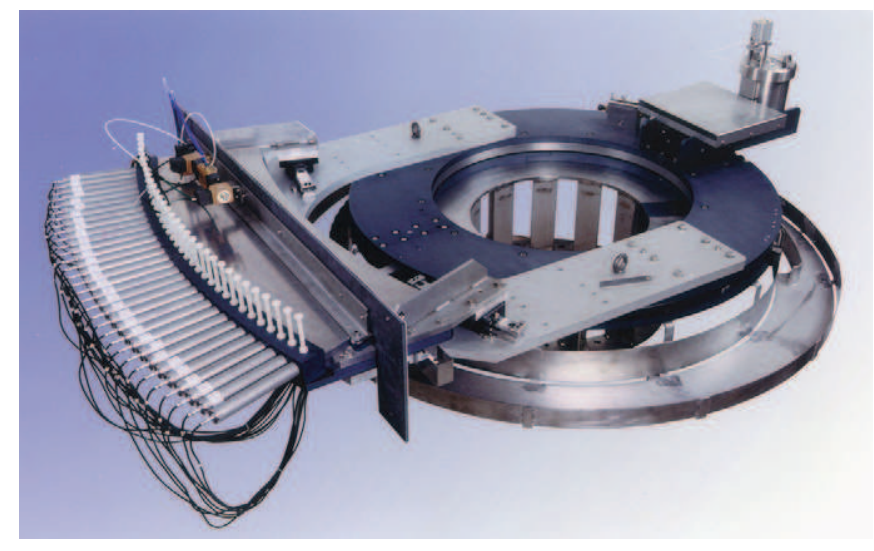

Fig. 4. IFPEN tomographic system, from Boyer and Fanget (2002), on the right: gamma ray source, on the left: 32 transducers for detection.

performed in operating conditions are combined with the calibration so that both experiments allow reconstructing the liquid spatial distribution. Once raw data corresponding to the attenuation in the column are collected from the tomographic system control software, a data processing algorithm developed at IFP Energies nouvelles (IFPEN) is used in order to get liquid hold-up maps at a given column axial position. The reconstruction code uses a classical filtered backprojection algorithm that allows calculating the liquid hold-up at a given point of the attenuation matrix as described in the work of Boyer and Fanget (2002). From this study, the absolute error on phase fraction is considered lower than $3 \%$. As far as the reconstruction algorithm is concerned, these authors pointed out higher errors in zones with abrupt density variations but which are still inferior to $5 \%$. These zones include wall zone (over $13 \mathrm{~mm}$ width). In present experiments we have tested the repeatability of the measurements. From data scattering we also conclude that the relative error on liquid hold-up is globally less than $3 \%$ and remains inferior to $5 \%$ even when experiments are reproduced one week after.

\subsection{Operating conditions and phases physical parameters}

Experiments were carried out using either water or monoethanolamine with $30 \%$ mass fraction in water (MEA $30 \mathrm{wt} \%$ ). Air was used for gas phase at column pressure of $1 \mathrm{bar}$. The physical properties of liquid phases are given in Table 1 for the mean operating temperature. Gamma ray tomography measurements were carried out for operating conditions reported in Tables 2 and 3. We explored various liquid loads ranging from 16 to $56 \mathrm{~m}^{3} / \mathrm{m}^{2} \mathrm{~h}$ which is the maximum liquid load allowed by the liquid distributor. For each liquid load, experiments were done at different gas flow rates that correspond to kinetic factors of $20 \%, 40 \%, 60 \%$ and $80 \%$ with respect to flooding conditions.

In Tables 2 and $3, q_{L}=Q_{L 0} / S$ is the liquid load and $F_{C}=Q_{G O} /$ $S \times \rho_{G}^{0.5}$ is the gas kinetic factor as commonly used in characterization of gas liquid contactors and $F_{V}$ is the gas kinetic factor at which flooding occurs for a given $q_{L}$ (in this work $F_{V}$ corresponds to flooding at the bottom of the packed bed and is the maximum value of $F_{C}$ in pressure drop curves).

For a given liquid load, typical regimes maps that are generally based on pressure drop through packed bed as well as liquid holdup as function of gas kinetic factor predict three possible flow regimes (Suess and Spiegel, 1992; Spiegel and Meier, 1992). For relatively low gas velocities, one expects a trickling flow where

Table 1

Liquid phases physical properties (Chih-Hao and Meng-Hui, 1997).

\begin{tabular}{llll}
\hline Liquid phase & $\mu(\mathrm{Pa} / \mathrm{s})$ & $\rho\left(\mathrm{kg} / \mathrm{m}^{3}\right)$ & $\sigma(\mathrm{mN} / \mathrm{m})$ \\
\hline Water $\left(20^{\circ} \mathrm{C}\right)$ & $1.00 \mathrm{E}-03$ & 998 & 73 \\
MEA 30 $\mathrm{wt} \%\left(20^{\circ} \mathrm{C}\right)$ & $2.48 \mathrm{E}-03$ & 1010 & 60 \\
\hline
\end{tabular}

Table 2

Operating conditions for Air/Water system.

\begin{tabular}{lllllll}
\hline$q_{L}\left(\mathrm{~m}^{3} / m^{2} \mathrm{~h}\right)$ & $F_{C}\left(\mathrm{~Pa}^{0.5}\right)$ & $\frac{F_{C}}{F_{V}}(\%)$ & $\mathrm{Re}_{L}$ & $\mathrm{Re}_{G}$ & $\mathrm{We}_{L}$ & $\mathrm{Fr}_{L}$ \\
\hline \multirow{2}{*}{16} & 0.74 & 20 & 71 & 921 & 1.2 & 2.3 \\
& 1.47 & 40 & & 1829 & & \\
& 2.21 & 60 & & 2749 & & \\
& 2.95 & 80 & & 6669 & & \\
28 & 0.61 & 20 & 124 & 778 & 1.9 & 2.7 \\
& 1.23 & 40 & & 1568 & & \\
36 & 1.84 & 60 & & 2346 & & \\
& 0.56 & 20 & 160 & 724 & 3.0 & 3.0 \\
& 1.12 & 40 & & 1446 & & \\
& 1.69 & 60 & & 2182 & & \\
56 & 2.25 & 80 & & 2904 & & \\
& 0.48 & 20 & 248 & 646 & 2.6 & 2.6 \\
& 0.95 & 40 & & 1279 & & \\
& 1.43 & 60 & & 1931 & & \\
\hline
\end{tabular}

Table 3

Operating conditions for Air/MEA 30 wt\% system.

\begin{tabular}{lllllll}
\hline$q_{L}\left(\mathrm{~m}^{3} / m^{2} \mathrm{~h}\right)$ & $F_{C}\left(\mathrm{~Pa}^{0.5}\right)$ & $\frac{F_{C}}{F_{V}}(\%)$ & $\mathrm{Re}_{L}$ & $\mathrm{Re}_{G}$ & $\mathrm{We}_{L}$ & $\mathrm{Fr}_{L}$ \\
\hline 16 & 0.71 & 20 & 29 & 893 & 1.0 & 1.4 \\
& 2.75 & 80 & & 3464 & & \\
28 & 0.64 & 20 & 51 & 833 & 1.7 & 1.6 \\
& 2.45 & 80 & & 3164 & & \\
\hline
\end{tabular}


interactions between gas and liquid are moderate. For higher gas kinetic factors wet pressure drop increases more rapidly with gas kinetic factor indicating subsequent interaction between gas and liquid. According to Suess and Spiegel (1992), this occurs for a ratio $F_{C} / F_{V}$ that is about $45 \%$. In this work, a large range of gas loads was considered in order to cover these two regimes. The third possible regime, which was not investigated in this work, is flooding regime where pressure drop increases infinitely with increasing gas load.

Gas Reynolds number is defined using equivalent hydraulic diameter of the packing as length scale:

$d_{h}=4 \varepsilon / a_{g}=1.6 \mathrm{~cm}$. This length scale is consistent with packing channels size (channel formed by two adjacent packing sheets) that is about $2 \mathrm{~cm}$. Effective gas velocity $U_{G}=U_{\mathrm{SG}} /\left(\varepsilon\left(1-h_{L}\right)\right)$ is considered to calculate gas Reynolds number where the superficial velocity is $U_{\mathrm{SG}}=Q_{\mathrm{GO}} / \mathrm{S}$.

We define the gas Reynolds number as follows:

$\operatorname{Re}_{G}=\frac{d_{h} \times U_{G}}{v_{G}}=\frac{d_{h}}{v_{G}} \times \frac{U_{S G}}{\varepsilon \times\left(1-h_{L}\right)}$.

As for liquid, Reynolds number is defined as follows (Alix and Raynal, 2008): $\operatorname{Re}_{L}=\left(4 \Gamma_{L} / \mu_{L}\right)$ where $\Gamma_{L}=\left(\rho_{L} \times U_{S L} / a_{g}\right)$ is the linear liquid flow rate per unit perimeter. This definition is consistent with fully wetting liquid film configuration in which film thickness $e$ is given by $h_{L}=e a_{g}$ (Raynal and Royon-Lebeaud, $2007)$ and effective liquid velocity by $U_{L}=U_{S L} /\left(\varepsilon h_{L}\right)$. As discussed in Section 4.2.2, liquid is most likely to flow as films and rivulets. This has been the motivation for calculation of liquid Reynolds number based on film thickness. However, inertia still can be considered in liquid films for highest Reynolds number as shown in simulations of Haroun et al. (2012). Actually, authors showed that recirculation zones may appear in packing cavities as liquid Reynolds number increases.

Liquid flow through packing may also be characterized by Weber and Froude numbers given in Tables 2 and 3 and defined, respectively, as follows:

$\mathrm{We}_{L}=\left(\rho_{L} \times U_{L}^{2} \times d_{h} / \sigma\right)$ and $\mathrm{Fr}_{L}=\left(U_{L}^{2} / g \times e\right)=\left(U_{L}^{2} \times a_{g} / g \times h_{L}\right)$ where $h_{L}$ denotes the measured liquid hold-up.

$\mathrm{We}_{L}$ and $\mathrm{Fr}_{L}$ do not vary significantly with operating conditions and their order of magnitude shows that inertia is important compared to gravity and surface tension effects.

\section{Results and discussion}

\subsection{Global pressure drop}

Fig. 5 shows pressure drop curves for different liquid loads including Air/Water and Air/MEA $30 \mathrm{wt} \%$ systems in the case of a point source-type liquid feed. The dry pressure drop curve matches with the one measured by Spiegel and Meier (1992) for similar conditions. In wet conditions, we observe two main regimes depending upon gas capacity factor. For low values of $F_{C}$, pressure drop is not too sensitive to liquid load in the considered range of operating conditions. In this regime, the slope of the curve of $d P$ versus $F_{C}$ is similar to that obtained in dry conditions. For higher values of $F_{C}$, as usually observed, pressure drop increases with liquid load with a higher slope of DP versus $F_{C}$ that is close to 2 indicating inertial regime. Results in wet conditions are in agreement with pressure drop behavior observed by Spiegel and Meier (1992) for similar liquid loads but are globally higher than them (Fig. 5). For the same liquid loads, loading as well as flooding in the case of Air/MEA $30 \mathrm{wt} \%$ system is observed to occur at capacity factors inferior to those of Air/Water system. This is expected since pressure drop increases

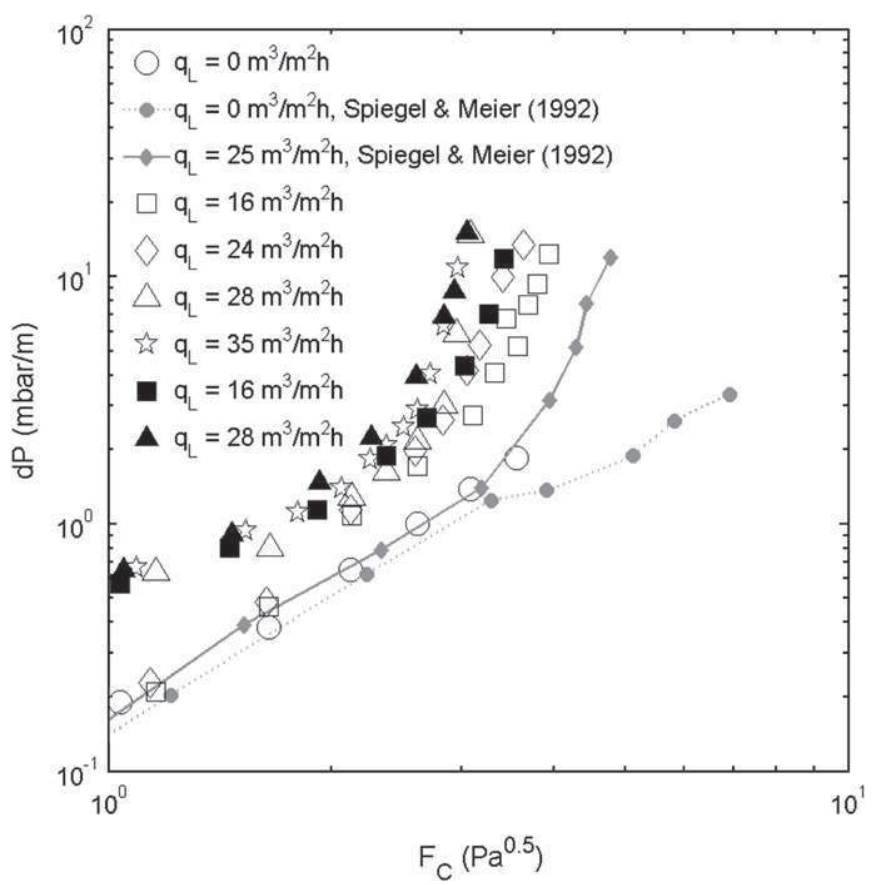

Fig. 5. Global pressure drop curves, open symbols: Air/Water system, closed symbols: Air/MEA 30\% system.

with liquid hold-up (Iliuta and Larachi, 2001) that increases with liquid viscosity as will be discussed in Section 4.2.2.

\subsection{Liquid hold-up distribution}

\subsubsection{Tomographic cross sectional maps}

Figs. 6 and 7 present liquid hold-up distributions over the column cross section for four axial positions and several gas and liquid flow rates. The maximum hold-up value in hold-up maps is set to $30 \%$ for all cases in order to have a good contrast on pictures and to compare them easily. Therefore, the points on the picture that have red (in color) or black (in grey scales) account for a liquid hold-up that is superior or equal to this limit value.

As previously mentioned in Section 3.2 the spatial resolution is $3 \mathrm{~mm}$. This means that one could have an insight into the scale of a packing channel (the channel formed by two adjacent metal sheets) in which width is approximately given by the equivalent hydraulic diameter of the packing: $d_{h}$, equal to $16 \mathrm{~mm}$ in the case of Mellapak 250.X. However, the obtained maps cannot describe the liquid distribution at the scale of the trickling liquid films. In fact, such films have been observed visually for the considered flow-rates and the order of magnitude of their thickness can be estimated, at the lowest liquid loads, by the following equation assuming a laminar fully developed flow over a smooth packing surface: $e=\left(3 \times U_{\mathrm{LS}} \times v_{L} / g \times a_{\mathrm{g}}\right)^{1 / 3}$ (Raynal and Royon-Lebeaud, 2007). The order of magnitude of the film thickness is thus around $0.2-0.4 \mathrm{~mm}$ for the considered flow-rates of gas and liquid. It is far less than the spatial resolution given by the measuring method.

From Fig. 6 one observes that whatever the flow conditions, the images at position $Z_{1}$ - which is the highest position in the packed bed that could be mechanically reached by the tomographic system - show clearly a liquid spot at the center of the cross section. This region of liquid accumulation is obviously due to the liquid feeding configuration consisting of a source of characteristic extension around $50 \mathrm{~mm}$ at the top of the bed. At this position $Z_{1}$, for all liquid loads and kinetic factors considered, the observed liquid spot already overspreads the 
a

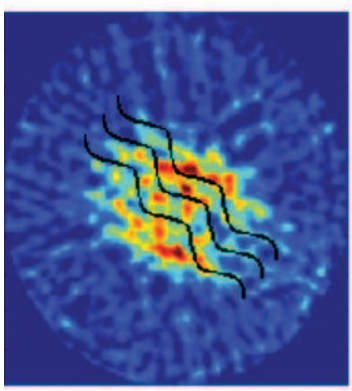

b

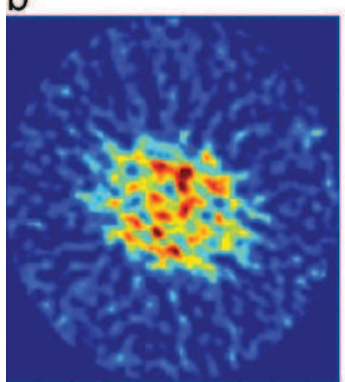

C

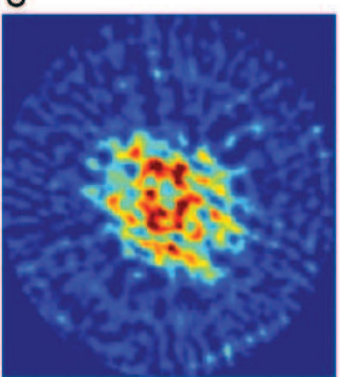

d

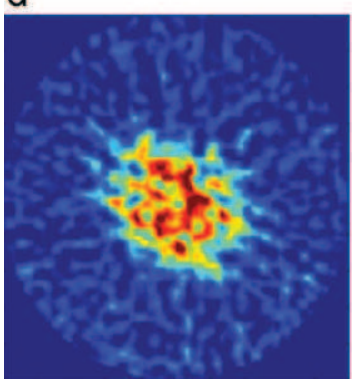

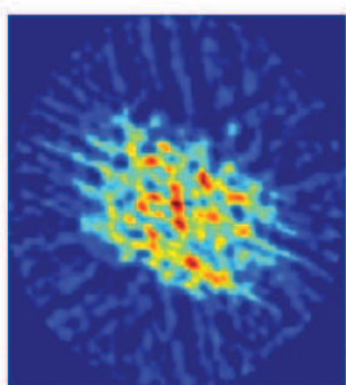
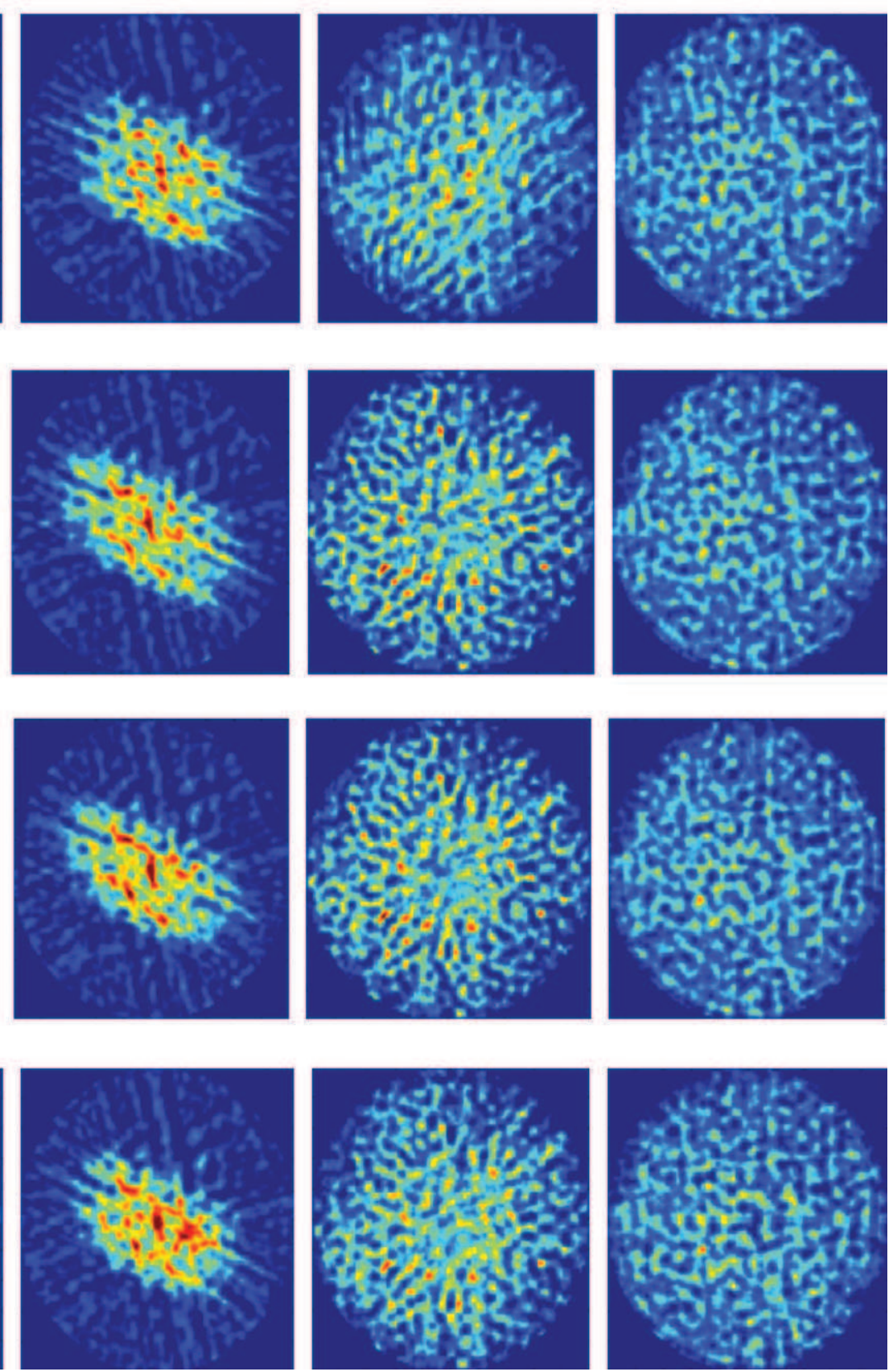

Fig. 6. Hold-up map for Air/Water system, $q_{L}=16 \mathrm{~m}^{3} / \mathrm{m}^{2} \mathrm{~h}$ : (a) $F_{V}=0.74 \mathrm{~Pa}^{0.5}$, (20\% Fc), (b) $F_{C}=1.47 \mathrm{~Pa}^{0.5}$, (40\% $\left.F_{V}\right),(\mathrm{c}) F_{C}=2.21 \mathrm{~Pa}{ }^{0.5}$, (60\% $\left.F_{V}\right),(\mathrm{d}) F_{C}=2.95 \mathrm{~Pa}{ }^{0.5}$, (80\% $\left.F_{V}\right)$. Positions from left to right are: $Z_{1}, Z_{2}, Z_{3}, Z_{4}$.

source extension. It is also important to notice that liquid can be present, even at moderate volume fractions (up to 5\%), around this central spot, over all the section of the column. This results from the impact of the liquid jet on the first packing element and from the propagation of the liquid through the structured packing in this element. In this region, liquid hold-up is associated to flowing liquid. In fact, each run starts from dry packed bed and measured average static liquid hold-ups are less than $1 \%(0.45 \%$ and $0.95 \%$ at position $Z_{3}$ were indeed measured for Air/Water and Air/MEA $30 \mathrm{wt} \%$ systems respectively). Actually, maps corresponding to position $Z_{2}$ in Figs. 6 and 7 show a relatively important spreading of the liquid in one specific direction. By making a tomographic measurement with a metallic mark put in the packed bed, liquid main spreading direction was proved to be consistent with the orientation of packing sheets for the considered packing layer as shown in the first cross section map in Fig. 6. For all considered liquid and gas flow-rates, the measurements performed at farther downstream locations clearly show, however, that liquid spreads significantly along the three first packing layers (positions $Z_{1}$ to $Z_{3}$ ) and that the spatial distribution of liquid loses any preferential orientation. When crossing different packing elements of alternative orientation, the dispersion mechanism becomes more and more isotropic (at least in the horizontal plane). Hold-up maps at position $Z_{4}$ show a spatial distribution of the liquid which is nearly homogeneous at a macroscopic scale but with still important liquid hold-up variations at local scales. This phenomenon is referred to by "channeling phenomenon" or "small scale maldistributions" (Hoek et al., 1986). 

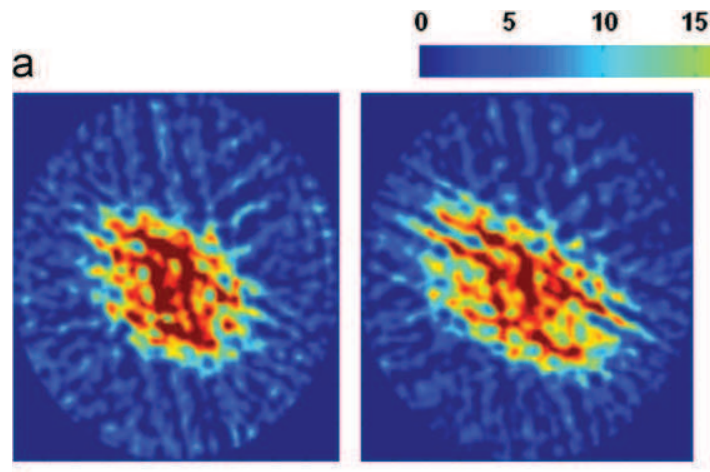

$15 \quad 20 \quad 25 \quad 30$

a
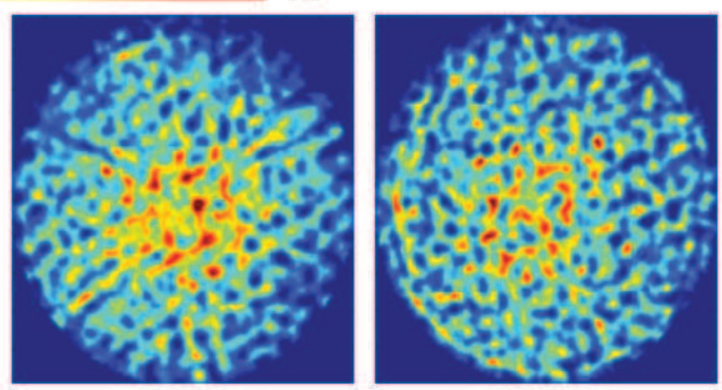

b
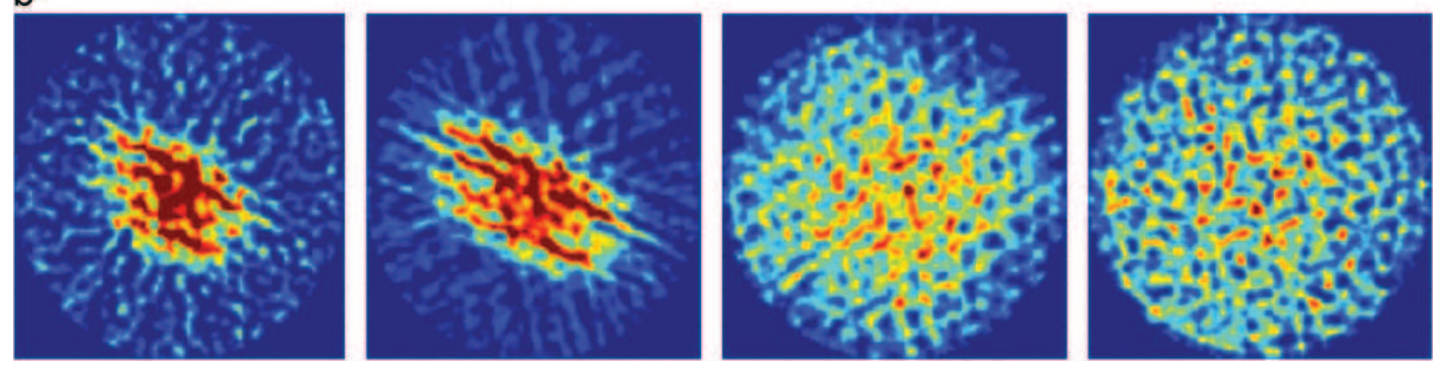

Fig. 7. Hold-up map for Air/Water system, $q_{L}=36 \mathrm{~m}^{3} / \mathrm{m}^{2} \mathrm{~h}$ : (a): $F_{C}=0.56 \mathrm{~Pa}^{0.5}$, (20\% $\left.F_{V}\right), q_{L}=36 \mathrm{~m}^{3} / \mathrm{m}^{2} \mathrm{~h}$ : (b): $F_{C}=2.25 \mathrm{~Pa}^{0.5}$, (80\% $\left.F_{V}\right)$, positions from left to right: $Z_{1}, Z_{2}, Z_{3}$ and $Z_{4}$.

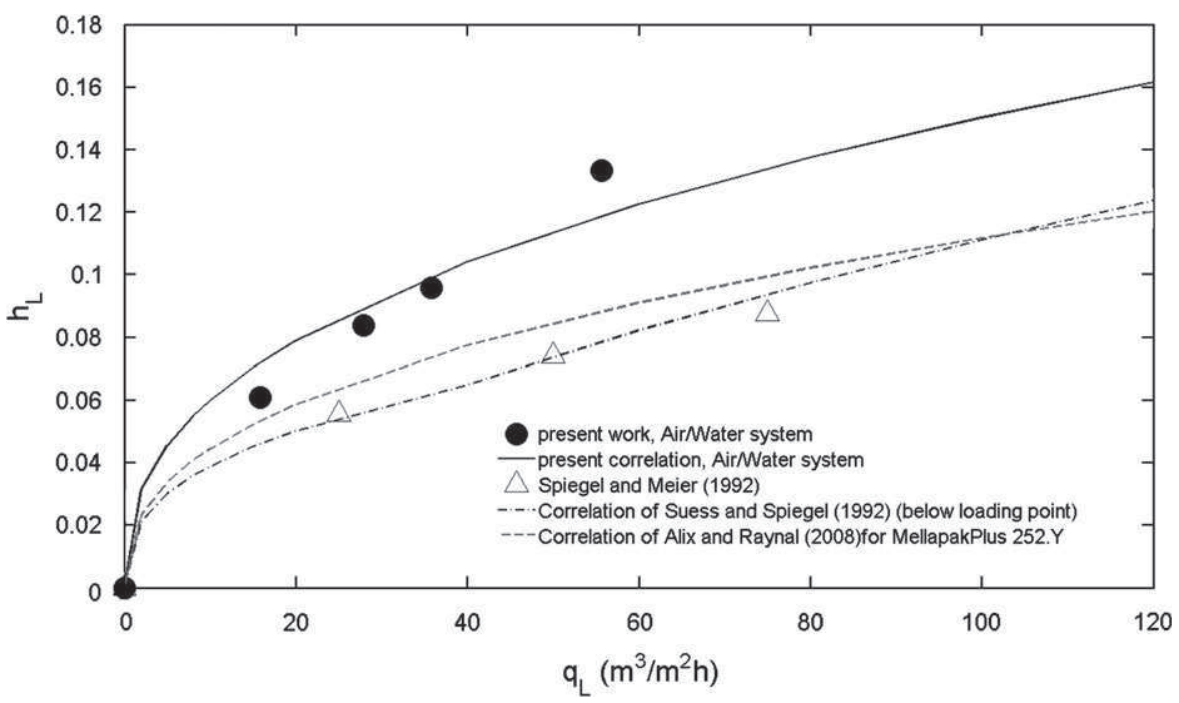

Fig. 8. Global cross-section averaged liquid hold-up for Air/Water system.

\subsubsection{Overall liquid hold-up}

Usually, the equation relating $h_{L}$ and the flow rates in homogeneous conditions is used to predict the liquid hold-up which is an important hydrodynamic parameter since it allows for calculating pressure drop as well as liquid effective velocity and further liquid-side mass transfer coefficient in a given packed bed (Alix and Raynal, 2008). In this study, we have calculated the cross section averaged liquid hold-up at the lower section of the column (position $Z_{4}$ in Fig. 1) since the most homogeneous liquid distribution is obtained at this position (Fig. 7). It is at first interesting to examine if, in this lower section, measurements made in homogeneous flows can be recovered. Then, it is also important to determine precisely the relation between our measurements of $h_{L}$ and the values of the liquid load $q_{L}$ in order to use it at local scale in heterogeneous flows by extrapolation. This will allow us to estimate the dispersion of the liquid using a model of the local liquid flow rate dispersion (Eqs. 3-5).
Figs. 8 and 9 show the evolution of the averaged liquid hold-up with the liquid load obtained in this study as well as in some previous works for Air/Water and Air/MEA $30 \mathrm{wt} \%$ systems. The results are described by the following relation:

$h_{L}=k \times\left(\frac{\mu_{L}}{\mu_{W}}\right)^{1 / 3} \times q_{L}^{0.4}$

in Eq. (6), $k=0.0209$ (with unit $(\mathrm{h} / \mathrm{m})^{0.4}$ ) when $q_{L}$ is given in $\mathrm{m}^{3} / \mathrm{m}^{2} / \mathrm{h}$ and $h_{L}$ is in the range [0 1 ].

The dependence of this relation upon viscosity and liquid load was inspired from work of Alix and Raynal (2008). Viscous term scaling is in agreement with laminar film theory and was shown to be robust for large range of liquid viscosities in co-current conditions by Sidi-Boumedine and Raynal (2005).

Several studies of the liquid hold-up under gas/liquid countercurrent flow conditions can be found in literature (Stichlmair et al., 


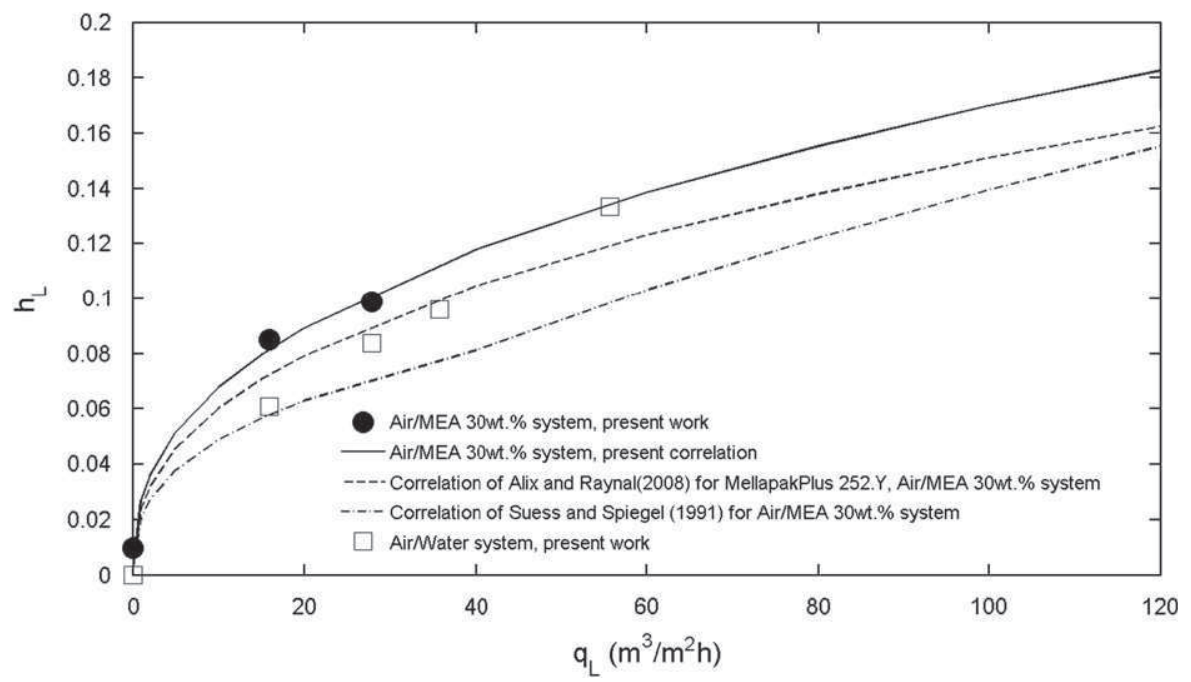

Fig. 9. Global cross-section averaged liquid hold-up for Air/MEA 30 wt\% and Air/Water systems.

1989; Billet and Schultes, 1991; Suess and Spiegel, 1992). In the present study, averaged hold-ups for Air/Water system are almost two times superior to those measured by Spiegel and Meier (1992) for the same packing as seen in Fig. 8. Likewise, Fig. 8 shows that correlation proposed by Suess and Spiegel (1992) under-estimates liquid hold-ups measured in this study. This is also the case for correlation suggested by Alix and Raynal (2008) for another structured packing that is MellapakPlus 252.Y which has same geometric surface and porosity than M250.X. Discrepancy between this model and experimental present data is; however, lower than that reported by Suess and Spiegel (1992) model. It is not that easy to explain that discrepancy but higher values of $h_{L}$ are consistent with higher values of pressure drop presented in Section 4.1.

Nevertheless, the exponent of $q_{L}$ in Eq. (6), equal to 0.4, is similar to that chosen by Alix and Raynal (2008). Suess and Spiegel (1992) suggested rather exponents equal to 0.37 for $q_{L}<=40 \mathrm{~m}^{3} / \mathrm{m}^{2} \mathrm{~h}$ and 0.59 for $q_{L}>40 \mathrm{~m}^{3} / \mathrm{m}^{2} \mathrm{~h}$. Charpentier et al. (1968) measured liquid hold-up for Rashig rings for different liquid loads with no gas flow. Based on their experiments, they calculated different exponents of $q_{L}$ depending on the flow regimes; they suggested an exponent equal to 0.33 for laminar films and 0.5 for laminar rivulets. Based on these results, if we assume that scaling laws evolve similarly for Rashig rings and Mellapack packings, the 0.4 exponent determined in the present study might indicate that liquid is more likely to flow as films and rivulets in laminar regime. However, Mellapak.250X geometry is different from that of Rashig rings and complex regimes of nonuniform films could also appear and explain for a part the change in hold-up laws. This has been observed in the numerical simulations of Haroun et al. (2012) who show probable recirculation zones in the packing cavities as liquid Reynolds number increases.

In Eq. (6) the gas flow rate does not appear. In fact, liquid holdup at a given liquid load was calculated by averaging liquid holdups obtained for all considered gas flow rates. This was consistent since liquid hold-up did not vary significantly with gas flow rates in the explored ranges for both Air/Water and Air/MEA $30 \mathrm{wt} \%$ systems. Such a result is expected for low gas flow rates that correspond to below-loading conditions. Liquid hold-up increases with gas flow for gas flow conditions that are above the loading point (flooding rate of $60 \%$ and $80 \%$ ) which is reported in the work of Suess and Spiegel (1992). Lower values of $h_{L}$ associated to higher values of $\mathrm{We}_{L}$ could explain that liquid films could be more deformable and sensitive towards gas flow rate in that work.

Also, static liquid hold-up does not appear in the correlation given by Eq. (6) since measurements with no liquid flow revealed negligible static hold-up for Air/Water and Air/MEA $30 \mathrm{wt} \%$ systems.

Liquid hold-up measurements for the case of the Air/MEA $30 \mathrm{wt} \%$ system are shown in Fig. 9. Eq. (6) was, likewise, used to correlate liquid hold-up to liquid load for this system. The correlation is satisfactory as shown in Fig. 9 and gives results that are close to those predicted by Alix and Raynal (2008). As for Air/Water system, higher hold-up values than in the work of Suess and Spiegel (1992) are observed. For tested liquid loads, measured values of $h_{L}$ are higher for Air/MEA $30 \mathrm{wt} \%$ than for Air/ Water system. This is well reproduced by Eq. (6).

We will use that equation to transform the local measurements of $h_{L}$ in local values of liquid flow rates $q_{L}$.

\subsubsection{Radial distribution of averaged liquid hold-up}

Liquid hold-up maps give a visual estimation of the liquid spreading across the packed bed. At a meso scale, liquid distribution can be considered as relatively homogeneous at bed outlet (position $Z_{4}$ ) for all the considered gas and liquid flow rates but with still maldistributions at small scales. In order to have more quantitative characterization of liquid spreading from a source point across the packed bed, averaged hold-up over concentric rings of width $\Delta r$ was considered. This allows investigating the precise influence of liquid load and gas kinetic factor on liquid spreading which cannot be directly seen through liquid holdup maps.

Using the local hold-up from the reconstructed hold-up matrix, averaged hold-up over a ring of radius $r$ is obtained using the following equation:

$h_{L}(r)=\frac{1}{2 \pi \times r \times \Delta r} \int_{0}^{2 \pi} \int_{r-\frac{\Delta r}{2}}^{r+\frac{\Delta r}{2}} h_{L}\left(r^{\prime}, \theta\right) \times r^{\prime} \times d r^{\prime} \times d \theta$

Radial liquid hold-up profiles are shown in Fig. 10 for a run corresponding to moderate liquid and gas flow rates. The averaged liquid hold-up profiles show the spreading of the liquid injected in the central region, with a noticeable radial expansion between section located at $Z_{2}$ and sections at $Z_{3}$, and then at $Z_{4}$. The changes between sections located at $Z_{1}$ and $Z_{2}$ are less important because both sections are just $6 \mathrm{~cm}$ apart. In Fig. 11, we have also reported, for several runs, the radial profiles of the liquid hold-up in self-similar coordinates. The hold-up $h_{L}(r, z)$ is normalized by its maximum value $h_{L \max }$, and the radial position $r$ is replaced by the self-similar coordinate $r / z^{1 / 2}$ deduced from Eq. (5). The various runs gather on a single curve, even 


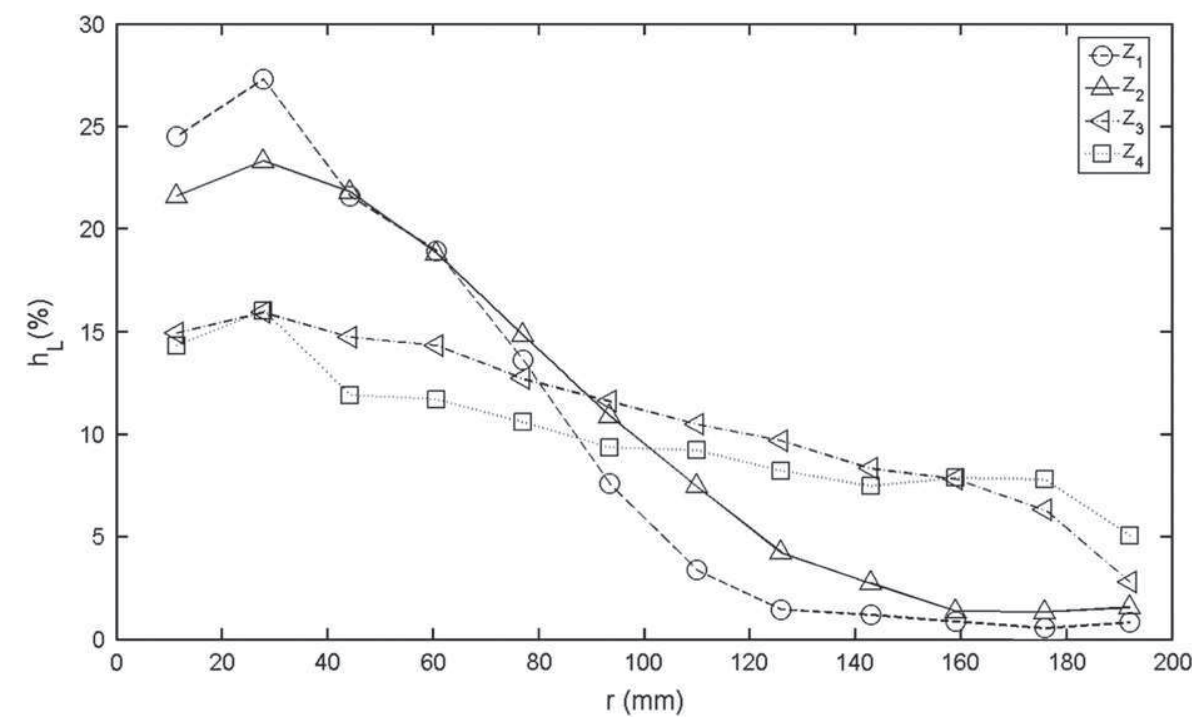

Fig. 10. Radial profiles of averaged liquid hold-up for Air/Water system, $q_{L}=28 \mathrm{~m}^{3} / \mathrm{m}^{2} \mathrm{~h}$ and $F_{C}=20 \% F_{V}=0.61 \mathrm{~Pa}^{0.5}$.

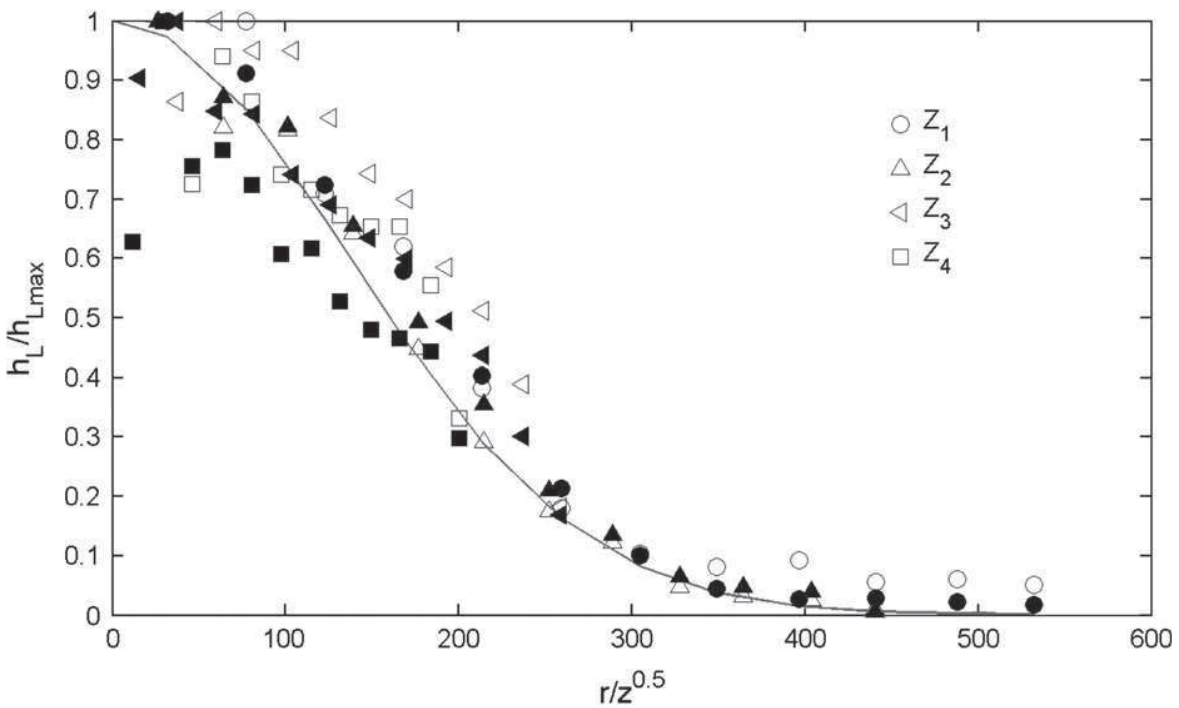

Fig. 11. Normalized liquid hold-up for Air/Water system. (Open symbols: $q_{L}=16 \mathrm{~m}^{3} / \mathrm{m}^{2} \mathrm{~h}$ and $F_{C}=60 \% F_{V}=2.21 \mathrm{~Pa}^{0.5}$, closed symbols: $q_{L}=36 \mathrm{~m}^{3} / \mathrm{m}^{2} \mathrm{~h}$ and $F_{C}=60 \%$ $F_{V}=1.69 \mathrm{~Pa}^{0.5}$, continuous curve: theoretical curve from Eq. (8)).

if some data scattering is still present. This is a strong indication that, whatever the inlet conditions, in the explored ranges, the average liquid hold-up can be represented by a master curve with a scaling indicating that dispersion controls the transverse motion of the liquid through the structured packed bed. The longitudinal evolutions of $h_{L 0}(z)=h_{L}(r=0, z)$ are shown in Fig. 12.

Actually, by combining Eqs. (3) and (6) assumed to be valid at a meso-scale, a self-similar spatial distribution of the liquid holdup can be obtained as follows:

$$
\left.\begin{array}{l}
h_{L}(r, z)=k^{\prime} \times q_{L}(r, z)^{0.4} \\
=k^{\prime} \times\left(\frac{Q_{L 0}}{4 \pi D_{r} z}\right)^{0.4} \times \exp \left(-0.4 \frac{r^{2}}{4 D_{r} z}\right) \\
=h_{L 0} \times \exp \left(-0.4 \frac{r^{2}}{4 D_{r} z}\right)
\end{array}\right\}
$$

with

$h_{L 0}(z)=k^{\prime} \times\left(\frac{Q_{L 0}}{4 \pi D_{r} z}\right)^{0.4}$

and $k^{\prime}=k \times\left(\mu_{L} / \mu_{W}\right)^{1 / 3}$.
Figs. 11 and 12 show that Eqs. (8) and (9) reproduce quite well the experimental data. Deviations to this simple theoretical solution are observed for positions near the column axis as can be seen in Fig. 11. This is due to the lack of accuracy of tomographic hold-up measurements at these particular locations. Deviation from theoretical model in Fig. 12 is also observed for large $q_{L}$ at the bottom of the bed which is, in all likelihood, due to interactions with the column wall. As discussed in Section 2, a general solution for radial evolution of liquid flow rate and thus liquid hold-up taking into account wall effects may be found in the works of Porter and Jones (1963) and Cihla and Schmidt (1958). Nevertheless, as explained in the works above, spread factors still need to be determined using infinite medium assumption which has been the focus of this work. Moreover it will be explained in Section 4.3 that spread factors were determined based on data relative to axial positions where liquid does not reach column walls.

Finally, the ability of the spreading model described in Section 2 to predict the radial distribution of $h_{L}$ and its longitudinal evolution is clearly observed for all the considered range of 


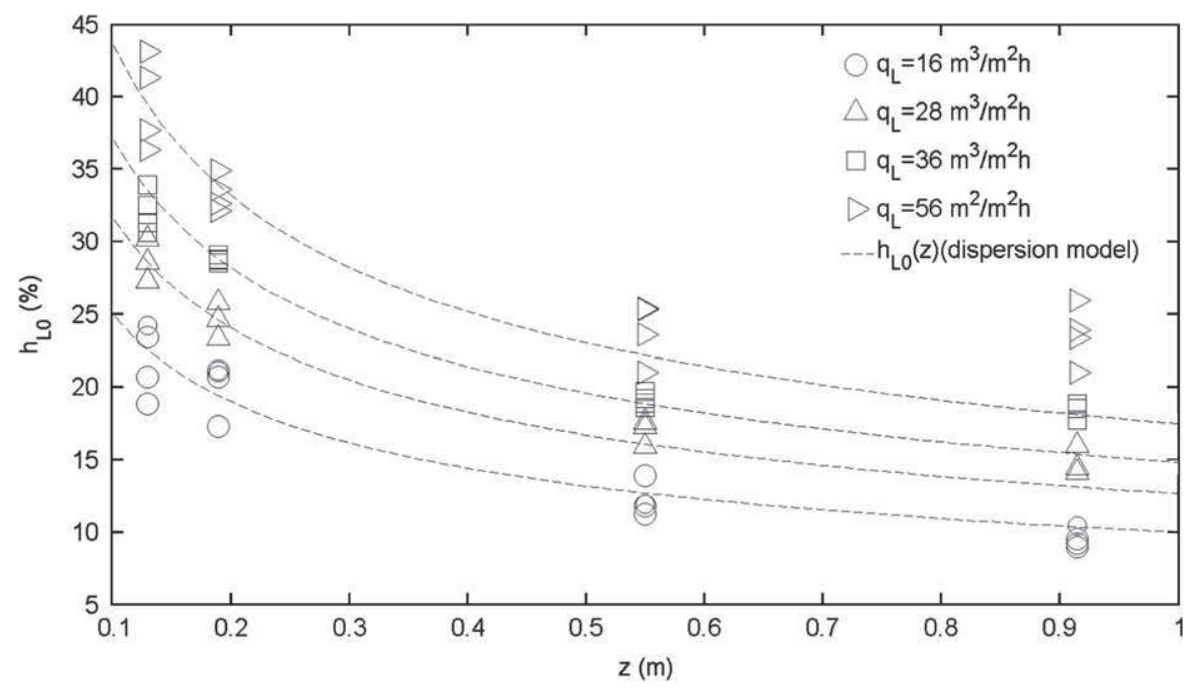

Fig. 12. Liquid hold-up on the axis $h_{L O}$ as function of axial coordinate $z(m)$ for Air/Water system. (Discrete points: hold-up from gamma tomography, -: Adjusted radial dispersion model). Values of $h_{L O}$ were obtained by extrapolation of measurements near column axis.

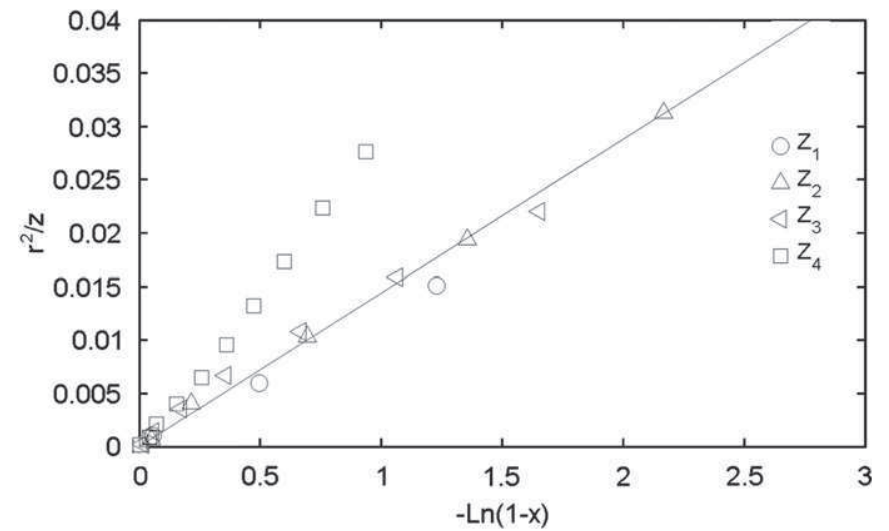

Fig. 13. Determination of radial spread factor for Air/Water system, $q_{L}=16 \mathrm{~m}^{3} / \mathrm{m}^{2} \mathrm{~h}$ and $F_{C}=80 \% F_{V}=2.95 \mathrm{~Pa}^{0.5}$.

experimental conditions. This implies that dispersion may be characterized by a spread factor $D_{r}$.

\subsection{Spread factor}

As explained previously in Section 2, liquid spreading from a single liquid source point can be characterized by a spread factor, $D_{r}$, which was proved to be pertinent to reproduce $h_{L}$ experimental distribution. Eq. (4) was, therefore, used in order to determine spread factors for each experimental condition in terms of liquid load and gas kinetic factor. Correlation given by Eq. (4) assumes a constant spread factor value for all axial positions in the bed; $D_{r}$ can be thus calculated so that the best linear fit of $r^{2} / z$ against $\operatorname{Ln}(1-x)$ is obtained using ideally data of all axial positions. Fig. 13 shows linear fit of $r^{2} / z$ against $\operatorname{Ln}(1-x)$ for the four considered axial positions. It shows also that data inherent to positions $Z_{1}, Z_{2}$ and $Z_{3}$ do gather on a single straight line of slope $4 x D_{r}$. However, data corresponding to position $Z_{4}$ gather over a greater slope. This is again explained by important wall effect at this particular position where liquid spreads enough to reach column walls while model described by Eq. (4) assumes liquid flows in an infinite medium. Therefore, spread factor for given liquid and gas flow rates is calculated using data relative to $Z_{1}, Z_{2}$ and $Z_{3}$.

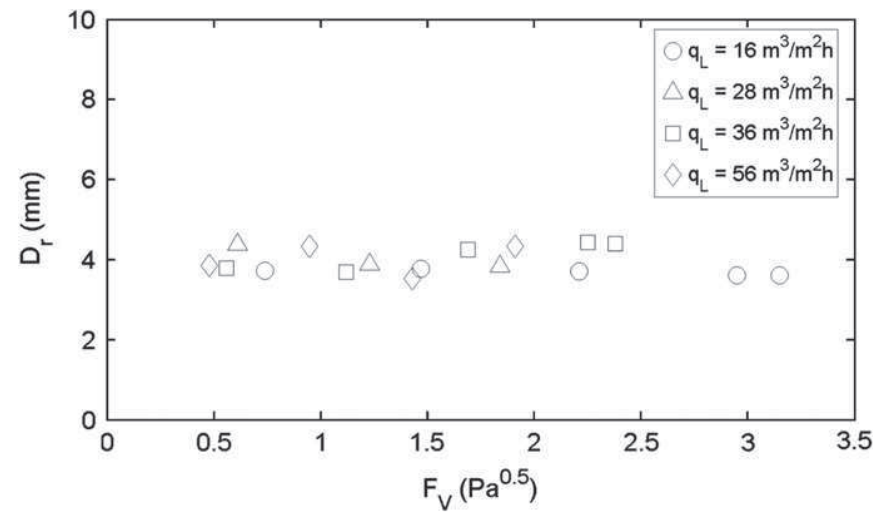

Fig. 14. Spread factor for Air/Water system as a function of $F_{C}$ for different $q_{L}$.

Table 4

Spread factors; comparison of Air/MEA 30 wt\% and Air/Water systems.

\begin{tabular}{llllll}
\hline \multirow{2}{*}{$q_{L}\left(\mathrm{~m}^{3} / \mathrm{m}^{2} \mathrm{~h}\right)$} & \multicolumn{2}{l}{ Air/MEA $30 \mathrm{wt} \%$} & & \multicolumn{2}{l}{ Air/Water } \\
\cline { 2 - 3 } \cline { 5 - 6 } & $\% F_{V}$ & $D_{r}(\mathrm{~mm})$ & & $\% F_{V}$ & $D_{r}(\mathrm{~mm})$ \\
\hline \multirow{2}{*}{16} & 20 & 3.9 & & 20 & 3.7 \\
& 80 & 3.4 & & 80 & 3.6 \\
& & & & \\
& 20 & 4.1 & & 20 & 4.4 \\
& 80 & 3.5 & & 80 & 3.8 \\
\hline
\end{tabular}

Fig. 14 presents the values of the spread factors determined for different gas and liquid flow rates. For the present operating conditions the spread factor associated to Mellapak 250.X packing does not vary with the gas kinetic factor for a given liquid load. Liquid load does not have any influence on the spread factor. Likewise, Table 4 shows that for the same liquid loads and kinetic factors, spread factor does not vary significantly when switching from Air/Water to Air/MEA wt 30\% system. This indicates that the dispersive mechanisms are dominated by geometrical effects and do not depend on viscosity or on gas and liquid flow rates. This result is consistent with observations of Hoek et al. (1986) who made experiments with no gas flow in random Raschig and 
Pall rings and stipulated that spread factor depends only on packing geometry. These authors determined a spread factor whose value was given by a correlation including $d_{p}$ which is the size of an equivalent particle of packing. This allows authors to calculate spread factors ranging from 1 up to $4 \mathrm{~mm}$ for the range of particle sizes they considered. Such correlation cannot be used in the case of structured packings since particle size does not have any sense for such packings with very high void fraction. Onda et al. (1972) also calculated spread factors ranging from 1 to $6 \mathrm{~mm}$ for ceramic Raschig rings and observed no dependence of spread factor on liquid flow rate or on dynamic viscosity in the range of $10^{-3}$ to $2.5 \times 10^{-3} \mathrm{~Pa}$.

Spread factors shown in Fig. 14 range from 3.6 up to $4.4 \mathrm{~mm}$; the mean value of $D_{r}$ being $3.9 \mathrm{~mm}$. The value of $D_{r}$ is similar to the size of the holes in the metal sheets and to the wave length of the texture on the metal packing sheets. Similarly it is not so different from the capillary length $l_{C}=\left(\sigma /\left(\rho_{L} g\right)\right)^{1 / 2}$ equal to $2.8 \mathrm{~mm}$ for Air/water system and $2.4 \mathrm{~mm}$ for Air/MEA $30 \mathrm{wt} \%$ system. It is thus difficult to conclude if small heterogeneities in the geometry control the dispersion or if rather surface tension controls the dispersion of liquid since it imposes the capillary length scale for random spreading of liquid.

In the case capillary length would control dispersion, and since $l_{C}$ does not vary significantly when using amines (usually used for carbon capture) one could expect same dispersion factors for these solvents and for water. This would not be probably the case for hydrocarbons in distillation processes since they have lower surface tension than water and amines.

In order to discuss the ability of $D_{r}$ to predict liquid dispersion in all investigated cases, experimental and predicted values of cumulated liquid flow rate $Q_{L}$ are confronted.

Fig. 15 shows normalized cumulated liquid flow rate against normalized radial coordinate. Experimental estimation of $Q_{L}$ is obtained from measurements of $h_{L}$ distribution using Eq. (6) for conversion into local liquid flow rate and Eq. (4). One should keep in mind that experimental cumulated liquid flow rates which correspond to discrete points in Fig. 15 was normalized by the effective liquid flow rate $Q_{0}$ that passes through the column cross section. Such flow rate is calculated for each axial position separately. Use of liquid hold-up correlation to predict liquid flow rate at local scales does not produce large variations of $Q_{0}$ as compared to $Q_{L 0}$. Fig. 15 shows good correspondence between
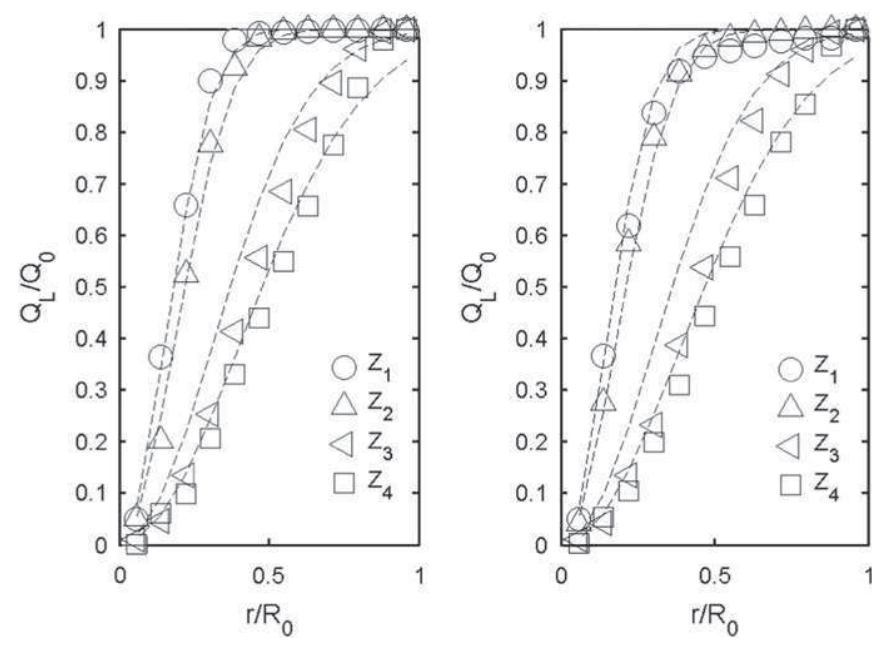

Fig. 15. Variation of normalized radial cumulated liquid flow-rate. Left: Air/Water system $\left(q_{L}=16 \mathrm{~m}^{3} / \mathrm{m}^{2} \mathrm{~h}\right.$ and $\left.F_{C}=80 \% \quad F_{V}=2.95 \mathrm{~Pa}^{0.5}\right)$, right: Air/MEA $30 \%$ $\left(q_{L}=16 \mathrm{~m}^{3} / \mathrm{m}^{2} \mathrm{~h}\right.$ and $\left.F_{C}=80 \% F_{V}=2.75 \mathrm{~Pa}^{0.5}\right)$. Discrete points: cumulated flow rate calculated from experimental measurements, continuous curves: flow rate calculated from radial dispersion model (Eqs. (3) and (4) with experimental value of $D_{r}$ ). liquid flow rates calculated from global hold-up model and radial dispersion model for Air/Water as well as Air/MEA $30 \mathrm{wt} \%$ systems.

Fig. 16a and b show parity diagrams of experimental cumulated liquid flow rates versus dispersion model. For all inlet conditions, the parity diagrams show a good consistency between measurements and predictions of the radial dispersion model. The most important deviations are observed at position $Z_{4}$ as previously discussed in this section due to important wall effect that is not taken into account by the model.

Nevertheless, the dispersion model remains globally robust for most liquid and gas flow rates.

\subsection{Liquid hold-up at packing elements junctions}

Tomographic measurements were carried out in order to have an insight into liquid hold-up at the contact surface between two packing units and determine its impact on liquid distribution.

In fact, accumulation of liquid in this zone was previously reported by Alix and Raynal (2008) as well as Suess and Spiegel (1992) who suggested that flooding occurs initially at junctions between packing units. Toye et al. (2005) who carried out X-ray tomography on Mellapak 250.Y reported the same observation with a global hold-up at junctions that was twice as high as in the interior of the packing unit. Our experiments confirm that liquid accumulates at packing junction that corresponds to position $Z_{j}$ (Fig. 1). This accumulation is clearly detected when one compares liquid hold-up distribution at position $Z_{j}$ with those at positions $Z_{2}$ and $Z_{3}$ (Fig. 17). But it is important to notice that the global increase of the liquid hold-up does not participate in redistribution of the liquid flow rate across the section. Liquid accumulation at junction does not improve liquid spreading from the source point in the packed bed. The hold-up distribution at position $Z_{3}$ is, in fact, still affected by injection conditions. At the junction between packing elements the local liquid velocities may be slowed down while the local liquid flow rate may be maintained, consistent with the increase of the liquid hold-up and the absence of homogenization. This accumulation is expected to result from capillary effects that generate a liquid film attached to the extremities of the packing metal sheets. This may create additional resistance to liquid and gas flow and then increase pressure drop.

Moreover, we have performed a specific experiment to test this proposal. As explained in Fig. 18, the end of the metal sheets of a packing element located just upstream of $Z_{j}$ has been cut with a triangular saw-like shape all along the portion of area of the cross section in order to avoid smooth contact between packing sheets. One single strip at the center of the contact surface has been let unmodified as shown in Fig. 18. For this geometry, liquid hold-up measurements have been performed with a homogeneous injection of liquid and of gas. Fig. 19 shows that with the saw-like shape there is much less liquid accumulation in that zone. This could be explained by breaking the capillary liquid film since contact between packing sheets is subsequently reduced. In Fig. 19, one can easily notice accumulation in the uncut zone of the junction (zone defined by black lines) which confirms that smooth contact between two packing units is responsible for liquid accumulation at that zone especially for high liquid loads. This, combined with redirection of the gas flow at packing layers junctions inducing higher gas local velocities, explains why packings with bent ends such as MellapakPlus, Flexipac HC, Montz type $\mathrm{M}$ packings can provide an increase in capacity compared to standard packings. Such a change in the geometry avoids gas acceleration; however it certainly does not change liquid accumulation, since the available wetted perimeter is kept constant. In the present case, there is probably no, or little 

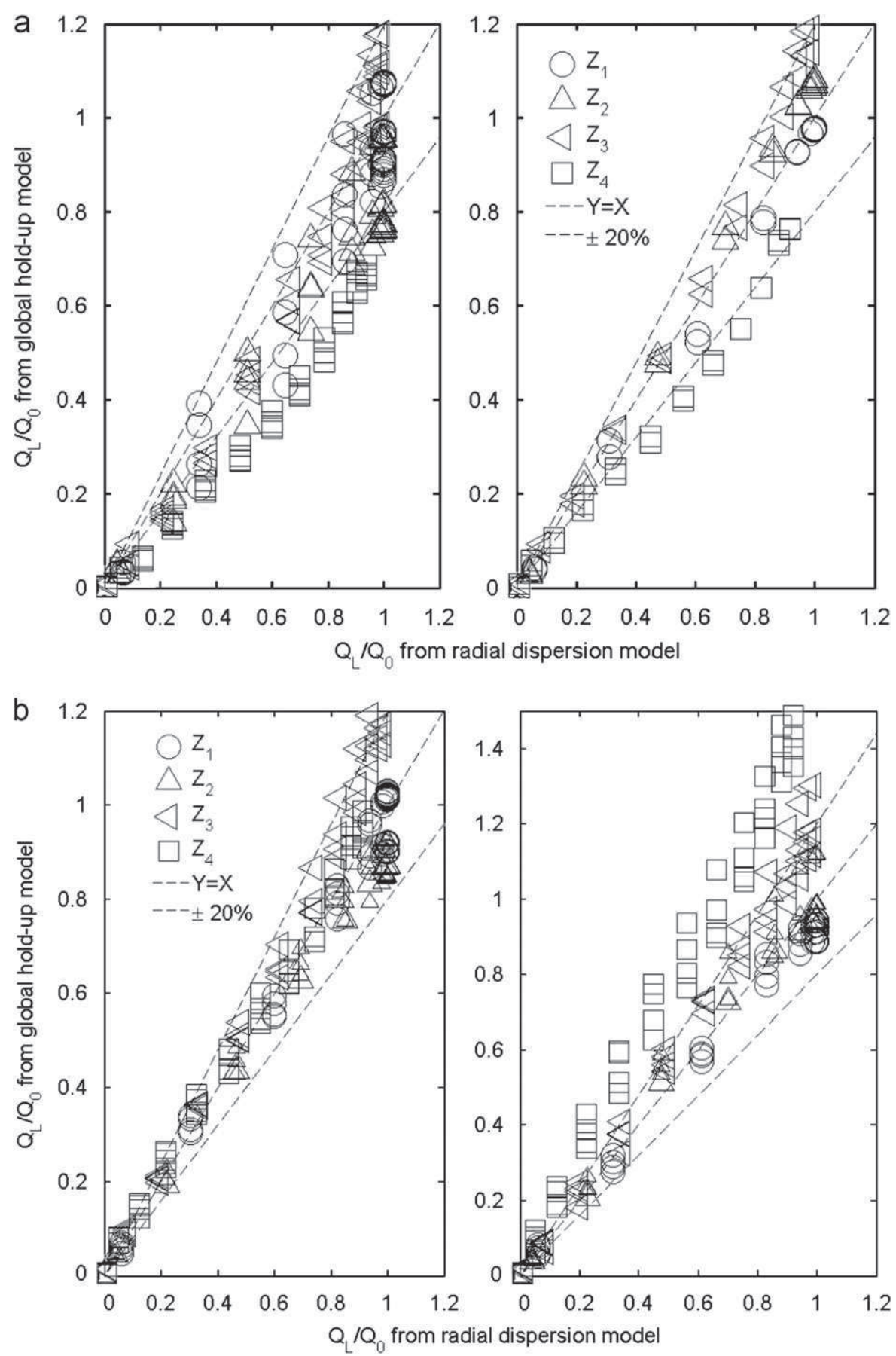

Fig. 16. Parity diagram of cumulated liquid flow rate. Global hold-up model versus radial dispersion model for all tested gas velocities (a) $q_{L}=16 \mathrm{~m}^{3} / \mathrm{m}^{2} \mathrm{~h}(\mathrm{left}), q_{L}=28 \mathrm{~m}^{3} / \mathrm{m}^{2} \mathrm{~h}$ (right) (Air/Water system); (b) $q_{L}=36 \mathrm{~m}^{3} / \mathrm{m}^{2} \mathrm{~h}$ (left), $q_{L}=56 \mathrm{~m}^{3} / \mathrm{m}^{2} \mathrm{~h}$ (right) (Air/Water system).

changes, in local gas velocities; however the liquid accumulation is significantly reduced as previously discussed. This is thus two different ways to solve the same issue of local important gas/ liquid interaction.

\section{Conclusion}

In this work, gamma ray tomography was used to investigate liquid distribution at different positions in a counter-current gasliquid column equipped with Mellapak 250.X structured packing for a large range of operating conditions. Liquid was fed from a source point at top of column and its spreading through the packed bed has been studied. Air was used as gas phase; water and MEA $30 \mathrm{wt} \%$ were used as liquid phases. This allowed us to investigate the effect of liquid viscosity on liquid spreading since MEA $30 \mathrm{wt} \%$, used as a reference solvent for $\mathrm{CO}_{2}$ capture, has a viscosity that is more than twice of that of water.

From the present original measurements and a simple dispersion model, liquid spread factors have been determined for four liquid flow rates and gas kinetic factors that were varied from $20 \%$ to $80 \%$ from flooding conditions. Liquid spread factor was found not to vary significantly with liquid and gas flow rates. Likewise, liquid viscosity is found to increase liquid hold-up but does not impact the spread factor. This has led us to stipulate that liquid dispersion depends only on packing geometry which is consistent 


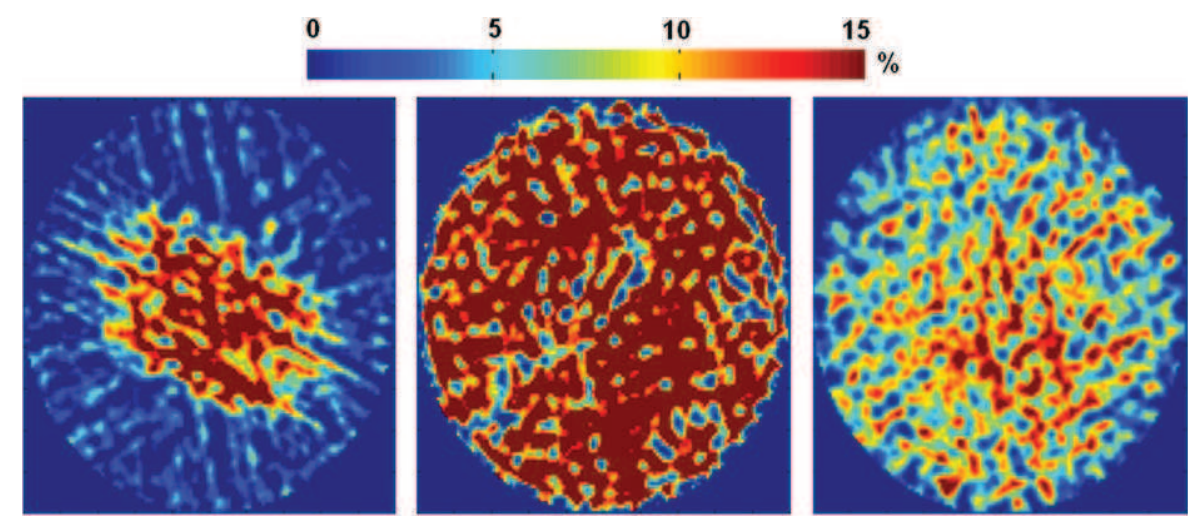

Fig. 17. Liquid hold-up maps, from left to right: positions $Z_{2}, Z_{j}$ and $Z_{3}, q_{L}=16 \mathrm{~m}^{3} / \mathrm{m}^{2} \mathrm{~h}, F_{C}=0.74 \mathrm{~Pa}^{0.5},\left(20 \% F_{V}\right)$.

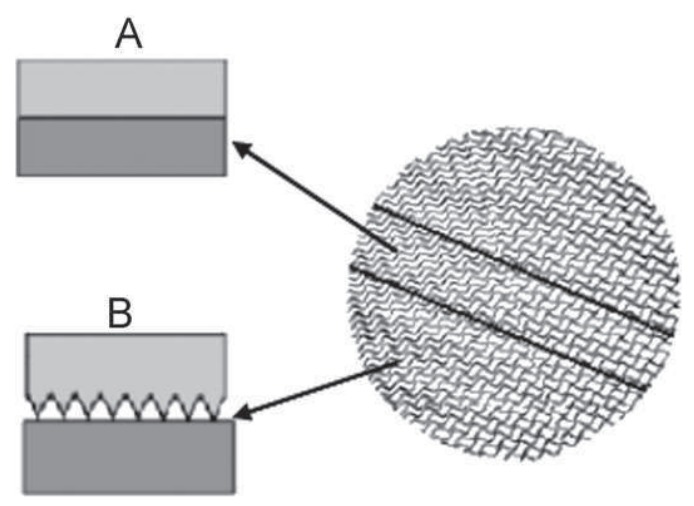

Fig. 18. Modification of contact surface at junction between two packing layers: region A: usual flat contact is maintained, region $\mathrm{B}$ : the end of the metal sheets has been cut.
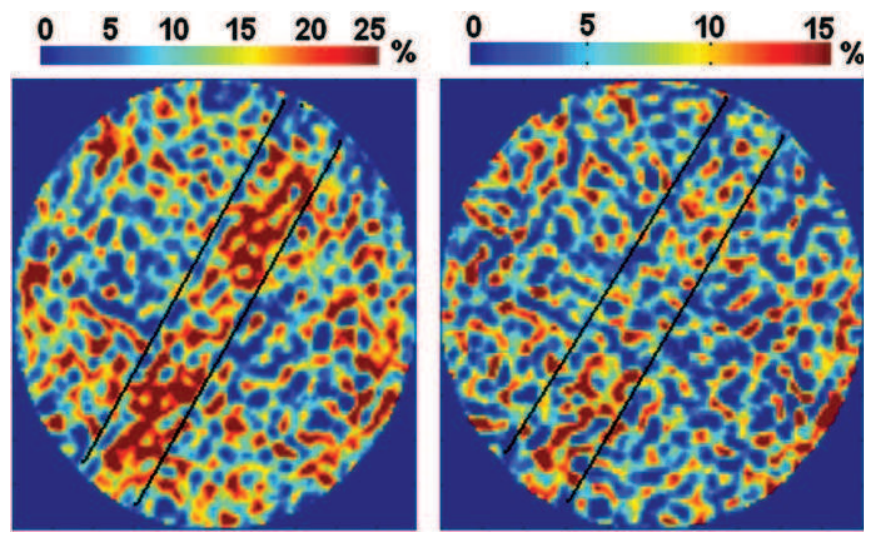

Fig. 19. Liquid hold-up maps at position $Z_{j}$ when contact surface is cut as shown in Fig. 18, from left to right: $Q_{L}=80 \mathrm{~m}^{3} / \mathrm{m}^{2} \mathrm{~h}$ and $Q_{L}=16 \mathrm{~m}^{3} / \mathrm{m}^{2} \mathrm{~h}, F_{V}=0 \mathrm{~Pa}^{0.5}$.

with the results found in literature for random packings, data inherent to structured packings being so far lacking.

The considered diffusion/advection model used to describe liquid dispersion was proved to be consistent with the experimental data in terms of radial hold-up and flow rate profiles. This model with associated spread factor values is thus proposed to predict spreading in structured packings. Such model could indeed inspire closure laws for two-fluid eulerian models for simulations of gas/liquid flows in packed column. Such approach seems very attractive for simulations of two-phase flow in packed beds since it allows to take into account the interactions between phases, interactions between fluids and packing solid surface as well as dispersive mechanisms. As shown by Raynal and
Royon-Lebeaud (2007) or Stemich and Spiegel (2001), CFD tools can be of high interest to study the interaction between distributing devices and the flow in the packed bed and accordingly define some design rules. However, such simulations performed for studying flow distribution at large scale issue are limited because they do not simulate the two phases, the liquid not being considered for the lack of closure laws representing liquid dispersion. Present measurements and associated dispersion model could be used in that purpose.

\section{Nomenclature}

Latin letters

$a_{g} \quad$ packing external surface area per unit volume of packed

$D_{r} \quad$ liquid spread factor, $\mathrm{m}$

D column diameter, $m$

$d_{h} \quad$ hydraulic diameter, $\mathrm{m}$

$d P \quad$ pressure drop, mbar $\mathrm{m}^{-1}$

e liquid film thickness, $\mathrm{m}$

$F_{C} \quad$ gas capacity factor, $\mathrm{Pa}^{0.5}$

$F_{V} \quad$ gas capacity factor at flooding conditions, $\mathrm{Pa}^{0.5}$

$\mathrm{Fr}_{L} \quad$ liquid Froude number

g gravity acceleration, $\mathrm{ms}^{-1}$

$h_{L} \quad$ liquid hold-up or volume fraction

$Q_{G 0} \quad$ gas flow rate, $\mathrm{m}^{3} \mathrm{~s}^{-1}$

$Q_{L 0} \quad$ liquid flow rate, $\mathrm{m}^{3} \mathrm{~s}^{-1}$

$Q_{L} \quad$ cumulated liquid flow rate, $\mathrm{m}^{3} \mathrm{~s}^{-1}$

$Q_{0} \quad$ effective liquid flow rate, $\mathrm{m}^{3} \mathrm{~s}^{-1}$

$q_{L} \quad$ liquid load, $\mathrm{m}^{3} \mathrm{~m}^{-2} \mathrm{~h}^{-1}$

$q_{L 0} \quad$ total liquid load, $\mathrm{m}^{3} \mathrm{~m}^{-2-} \mathrm{h}^{-1}$

$r \quad$ radial component in a cylindrical coordinate system

$\operatorname{Re}_{L} \quad$ liquid film Reynolds number

$\operatorname{Re}_{G} \quad$ gas Reynolds numbers

$S \quad$ packed bed cross-section, $\mathrm{m}^{2}$

$U_{\mathrm{SG}} \quad$ gas superficial velocity, $\mathrm{ms}^{-1}$

$U_{\mathrm{SL}} \quad$ liquid superficial velocity, $\mathrm{ms}^{-1}$

$U_{G} \quad$ effective gas velocity, $\mathrm{ms}^{-1}$

$U_{L} \quad$ effective gas velocity, $\mathrm{ms}^{-1}$

$\mathrm{We}_{L} \quad$ liquid Weber number

$z \quad$ axial component in a cylindrical coordinate system

Greek letters

$\Gamma_{L} \quad$ linear liquid flow rate per unit perimeter, $\mathrm{kg} \mathrm{m}^{-1} \mathrm{~s}^{-1}$

$\varepsilon \quad$ packing void fraction, dimensionless

$\theta \quad$ angular component in a cylindrical coordinate system 


\section{$\mu \quad$ dynamic viscosity, $\mathrm{Pa} \mathrm{s}^{-1}$ \\ $v(=\mu / \rho)$ kinematic viscosity, $\mathrm{m}^{2} \mathrm{~s}^{-1}$ \\ $\rho$ density, $\mathrm{kg} \mathrm{m}^{-3}$ \\ $\sigma \quad$ surface tension, $\mathrm{mN} \mathrm{m}^{-1}$}

\section{Subscripts}

$\begin{array}{ll}L & \text { liquid phase } \\ G & \text { gas phase } \\ W & \text { water }\end{array}$

\section{References}

Alix, P., Raynal, L., 2008. Liquid distribution and liquid hold-up in modern high capacity packings. Chem. Eng. Res. Des. $86,585-591$

Bemer, G.G., Zuiderweg, F.J., 1978. Radial liquid spread and maldistribution in packed columns under different wetting conditions. Chem. Eng. Sci. 33, 1637-1643.

Billet, R., Schultes, M., 1991. Modelling of pressure drop in packed columns. Chem. Eng. Technol. 14, 89-95.

Boyer, C., Fanget, B., 2002. Measurement of liquid flow distribution in trickle bed reactor of large diameter with a new gamma-ray tomographic system. Chem. Eng. Sci. 57, 1079-1089.

Charpentier, J.C., Prost, C., Le Goff, P., 1968. Ecoulement ruisselant de liquide dans une colonne à garnissage. Détermination des vitesses et des débits relatifs des films, des filets et des gouttes. Chim. Ind., Génie Chim. 100, 653-665.

Chih-Hao, H., Meng-Hui, L., 1997. Densities of aqueous blended amines. J. Chem. Eng. 42, 502-507.

Cihla, Z., Schmidt, O., 1958. Studies of the behaviour of liquids when freely trickling over the packing of cylindrical tower. Collect. Czech. Chem. Commun. 23, 569-577.

Edwards, D.P., Krishnamurthy, K.R., Potthof, R.W., 1999. Development of improved method to quantify maldistribution and its effect on structured packing column performance. IChemE 77 (Part A), 656-662.

Hoek, P.J., Wesselingh, J.A., Zuiderweg, F.J., 1986. Small scale and large scale liquid maldistribution in packed columns. Chem. Eng. Res. Des. 64, 431-449.

Haroun, Y., Raynal, L., Legendre, D., 2012. Mass transfer and liquid hold-up determination in structured packing by CFD. Chem. Eng. Sci. 75, 342-348.
International Energy Agency, 2009, Technology Roadmap-CCS, IEA Ed. Available from:〈http://www.iea.org/papers/2009/CCS_Roadmap.pdf $\rangle$.

Iliuta, I., Larachi, F., 2001. Mechanistic model for structured-packing-containing columns: irrigated pressure drop, liquid holdup, and packing fractional wetted area. Ind. Eng. Chem. Res. 40, 5140-5146.

Lappalainen, K. Mannienen, M., Alopaeus, V., 2009. CFD modeling of radial spreading of flow in trickle-bed reactors due to mechanical and capillary dispersion. Chem. Eng. Sci. 64, 207-218.

Mewes, D., Loser, T., Millies, M., 2009. Modelling of two-phase flow in packings and monoliths. Chem. Eng. Sci. 54, 4729-4747.

Mohamed Ali, A., Janses, P., Olujic, Z., 2003. Experimental characterisation and CFD simulation of gas distribution performance of liquid redistributors and collectors in packed columns. Chem. Eng. Res. Des. 81, 108-115.

Olujic, Z., Van Baak, R., Haaring, J., 2006. Liquid distribution behaviour of conventional and high capacity structured packings. IChemE. (Symposium Series NO. 152).

Onda, K., Takeuchi, H., Maeda, Y., Takeuchi, N., 1972. Liquid distribution in packed column. Chem. Eng. Sci. 28, 1677-1683.

Porter, K.E., Jones, M.C., 1963. A theoretical prediction of liquid distribution in a packed column with wall effects. Trans. Inst. Chem. Eng. 41, 240-247.

Raynal, L., Bouillon, P.A., Gomez, A., Broutin, P., 2011. From MEA to demixing solvents and future steps, a roadmap for lowering the cost of post-combustion carbon capture. Chem. Eng. J. 171, 742-752.

Raynal, L., Royon-Lebeaud, A., 2007. A multi-scale approach for CFD calculations of gas-liquid flow within large size column equipped with structured packing. Chem. Eng. Sci. 62, 7196-7204.

Sidi-Boumedine, R., Raynal, L., 2005. Influence of the viscosity on the liquid holdup in trickle-bed reactors with structured packings. Catal. Today 105, 673-679.

Spiegel, L., Meier, W., 1992. A generalized pressure drop model for structured packings. IChemE, 85-94 (Symposium Series NO. 128).

Stemich, C., Spiegel, L., 2001. Characterization and quantification of the quality of gas flow distributions. Chem. Eng. Res. Des. 89 (8), 1392-1396.

Stichlmair, J., Bravo, J.L., Fair, J.R., 1989. General model for prediction of pressure drop and capacity of counter-current gas/liquid packed columns. Gas Sep. Purif., 19-28.

Suess, P., Spiegel, L., 1992. Hold-up of Mellapak structured packings. Chem. Eng. Process. 31, 119-124.

Toye, D., Crine, M., Marchot, P., 2005. Imaging of liquid distribution in reactive distillation packings with a new high-energy x-ray tomography. Meas. Sci. Technol. 16, 2213-2220. 